\title{
The economics of water conservation regulations under uncertainty: An application to Alberta's Lower Athabasca River Region
}

\author{
Yichun Huang ${ }^{1} \quad$ Margaret Insley ${ }^{2}$
}

Working Paper, July 4, 2020

\begin{abstract}
Large water demands by the mining industry are of increasing concern around the world. Command and control water regulations may be highly inefficient. The cost of a specific command and control water management policy is studied for an oil sands mining operation in Canada, where restrictions on water withdrawals vary with fluctuations in the river. A dynamic stochastic optimal control model is specified for a firm choosing production, water use, and the timing to build a water storage facility, under conditions of uncertain oil prices and uncertain water withdrawal limits. A numerical solution of an HJB equation is implemented to determine the difference in value and optimal controls for the oil-producing asset, with and without water restrictions. The cost of the restrictions is estimated to be quite small given the current reserve base and capacity of the industry. The marginal cost of tightening restrictions is non-monotonic with respect to price volatility.
\end{abstract}

Keywords: water conservation regulations, oil sands, storage, stochastic optimal control, Hamilton-Jacobi Bellman equation, uncertain river flow, uncertain oil price

JEL codes: Q30, Q40, C61, C63

\footnotetext{
${ }^{1}$ Department of Economics, University of Waterloo, Canada, y247huan@uwaterloo.ca

${ }^{2}$ Department of Economics and The Water Institute, University of Waterloo, Canada, margaret.insley@uwaterloo.ca
} 


\section{Introduction}

The management of scarce water supplies is an issue of increasing concern in many areas of the world and is exacerbated by uncertainty surrounding the impacts of a warming planet on water availability. Surface and ground water sources are typically exploited as common pool resources meeting diverse needs. As noted by Libecap and Barbara (2012), the fluid nature of water and the fact that it is used sequentially or simultaneously by many parties hinder our ability to define an efficient property rights system. Externalities and third party effects of water diversion are pervasive. The resource extraction industry is responsible for large withdrawals of water around the world, and competition for water supplies may put industry operations into conflict with local communities. These conflicts arise when the water demands for resource extraction encroach on the water supplies used for other human activities or compromise aquatic ecosystems. Protection of the public interest requires that governments around the world specify limits on water withdrawals and enforce legal and regulatory requirements regarding water access rights.

Media and industry reports make it clear that competition for water supplies is of increasing concern for firms involved in resource extraction. Water availability has been reported as being one of the biggest problems facing mining firms today. ${ }^{3}$ Similar concerns have been raised regarding shale gas development. ${ }^{4}$ Regulatory responses vary across jurisdictions, depending on the state of water supplies, the nature of other competing uses, as well as the existing political, legal and regulatory frameworks. Thomashausen et al. (2018) review the legal framework regulating water use for gold and copper mining in eight different countries. All countries surveyed required mining firms to obtain water licenses or permits as well as undertake some sort of environmental assessment. The basis for allocating water shares varies, and is typically some combination of riparian or prior appropriation rights, as well as rules about the transfer or trading of water rights.

The focus of this paper is on the assessment of the economics of water regulations imposed on resource extraction activities. To this end, we examine the regulation of mining operations

\footnotetext{
${ }^{3}$ See for example a July 272014 Financial Times article "Water scarcity and rising energy costs threaten mining industry"; a Moody's Investor Service report "Global Mining Industry: Water scarcity could increase rating pressure on global mining companies", February 14, 2013; and Toledano and Roorda (2014).

${ }^{4}$ See discussions in Vengosh et al. (2014) and Holding et al. (2017).
} 
in the Alberta oil sands limiting fresh water withdrawals from the Lower Athabasca River. Our modelling approach and conclusions provide insights for public policy in Alberta's oil sands, as well as in other similar industries throughout the world.

The large ramping up in the scale of oil sands activity in the early 2000s brought public attention to the quantity of both surface and groundwater withdrawals, as well as many other environmental impacts that have been well documented in the literature. ${ }^{5}$ Fresh water withdrawals from the Athabasca River by open pit mining operations have the potential to negatively impact the health of the river ecosystem, particularly during low-flow periods. In addition, the river sustains the livelihood and culture of First Nations and Metis communities in the area, and low flow hinders navigation on the river. Predictions of continued industrial expansion and growing population as well as expectations that water flows may be reduced in the future due to the effects of a warming climate exacerbated concerns. In response to these concerns, the Alberta government drafted a river management plan for the Lower Athabasca River to limit withdrawals according to river conditions. The management plan was first imposed in 2007 and is described in the Phase 1 Framework (Alberta and Canada, 2007). This Phase 1 Framework was intended to address immediate needs for water protection based on currently available evidence, with the intention that the regulations would be revised in future based on the results of further research. Additional research and consultation with stakeholders were carried out over the subsequent seven years, resulting in a revision to the water regulations released in 2015 as the Phase 2 Framework (Alberta, 2015). The Phase 2 regulations imposed a somewhat finer classification of water flow conditions, but are otherwise similar to the Phase 1 regulations. In this paper we demonstrate the determination of the economic cost of this command and control regulation, using the details of the Phase 1 specification, which simplifies the analysis without compromising the results.

The Alberta Framework (both Phases 1 and 2) specifies aggregate permitted water withdrawals by oil sands mining firms depending on river conditions. When river flows are below certain specified thresholds, cutbacks in water diversions are required. In the Phase 1 Framework, river conditions are categorized as being in one of red, yellow or green zones which signifies low, medium and abundant water flows, respectively. Alberta's water management Framework is layered upon an existing prior appropriation regime, or "First in Time, First

\footnotetext{
${ }^{5}$ See Griffiths et al. (2006), Gosselin et al. (2010), Squires et al. (2010), and Bruce (2006) for details.
} 
in Right" (FITFIR), whereby senior license holders are given priority over more junior water license holders. However with the implementation of the Framework, oil sands firms were asked to develop water sharing rules to be implemented in the red or yellow zones, rather than following the rules of FITFIR (Adamowicz et al., 2010). River flows are highly seasonal and the Phase 1 Framework encourages firms to store water during times of high water availability for use during times of shortfall.

The stated objective of the Alberta Framework is to "manage cumulative water withdrawals to support both human and ecosystem needs, while balancing social, environmental, and economic interests" (Alberta, 2015, p. 3). An assessment of the efficiency of Alberta's water regulations requires analysis of the marginal benefits and costs of the water restrictions to determine the level where total welfare is maximized. The costs will be felt mainly by oil sands firms in terms of lost profits. The benefits of water quantity restrictions are more diverse, reflecting the benefit of leaving additional units of water in the river. These may be benefits to the ecosystem or benefits to other users of the river. There is considerable scientific uncertainty over how much water can be safely diverted from the river without harming the aquatic ecosystem ${ }^{6}$, making it very difficult to pin down a reasonable estimate of the value of leaving more water in the river. While the marginal cost of water restrictions to firms is also unknown, it may be easier to assess than the marginal benefit of an additional unit of water to the ecosystem. A careful assessment of the marginal cost is useful in that it provides a lower bound for the marginal benefit in order for the regulation to be judged to be welfare improving.

For efficiency, water regulations should bring about an equalization of the marginal costs of compliance across individual firms in the industry. The Alberta water regulations are command and control with no mechanism to promote an efficient allocation of water across regulated firms. Alberta's water sharing rules do not consider the needs of new entrants nor the differing efficiency of water use of existing firms. Also noteworthy is that there are no

\footnotetext{
${ }^{6}$ See for example a CTV news report from March 19 2014, "Alberta's plan for Athabasca River 'pathetic,' not science-based: critics." by Bob Weber, The Canadian Press. This article quotes David Schindler, a University of Alberta ecologist who claims a lack of scientific evidence for the chosen water restrictions and argues that even a couple of inches less in the river can have a critical impact on fish habitat, bug populations, water quality, ground water etc. http://www.ctvnews.ca/sci-tech/ alberta-s-plan-for-athabasca-river-pathetic-not-science-based-critics-1.1735778 (accessed on January 11, 2020)
} 
stated financial penalties for oil sands firms violating water sharing agreements.

The broad purpose of this paper is to contribute to our understanding of the efficiency of command and control regulations for the industrial use of water in cases where the specific restrictions are tied with a stochastic environmental indicator. The specific contribution is to model the profit maximizing decisions of a typical oil sands project subject to Alberta's Phase 1 Framework and from this to construct the firm's marginal cost curve for a range of water withdrawal restrictions. A further objective is to consider the effect of the option to invest in water storage facilities on the firm's marginal cost curve. From the individual project marginal cost curve, a characterization of the industry marginal cost curve can be obtained and contrasted with possible marginal benefit curves.

The modelling of the economic cost of water restrictions is challenging because of the particular characteristics of the firm's decision problem. Water demands by oil sands firms are determined by their decisions about oil production. A firm chooses optimal production levels in the context of the optimal timing of depletion of the stock of oil reserves of a particular project. In the case of Alberta, oil reserves are publicly owned, and firms pay for the right to extract resources over specified time according to the terms of a license agreement. Firms also face restrictions on water extraction levels which are stochastic in nature, depending on river flows. If a firm chooses to install water storage, then the management of water storage levels is another component of the firm's decisions problem. Finally oil production, and hence water use, is affected by volatile oil prices determined in world markets. In summary, the firm's problem involves the optimal choice of oil production and the timing to install water storage facilities, given stochastic oil prices and water withdrawal restrictions, and given path dependent state variables - oil reserves and water inventory levels.

In this paper, the firm's decision is modelled as an optimal control problem, with oil prices described by a stochastic differential equation and water restrictions modelled as a Poisson process. The firm chooses at each time period over the life of a project how to comply with water restrictions, whether by curtailing production or investing in a water storage unit. A Hamilton-Jacobi-Bellman (HJB) equation is specified which describes the firm's optimal decision problem. The HJB equation is solved using a numerical method, as there is no closed form solution. A numerical example is developed for a hypothetical oil sands firm. The solution of the decision model provides estimates of the value of the a hypothetical oil 
sands project for a range of water restrictions, as well as the critical level for oil prices at which it would be optimal for a firm to invest in a water storage facility. By varying water restriction levels, we are able to estimate the marginal cost in terms of the value to the firm of relaxing the restrictions at the margin. Our analysis is from the perspective of a typical or average oil sands firm. Due to the lack of publicly available data, we do not consider a case when there are productivity differences between different firms. For illustrative purposes, we do scale up the analysis for the typical firm to consider the implications at the industry scale, assuming all firms have equal productivity of water use. While this model is applied to a specific example in Alberta, the approach and conclusions are of relevance for other mining projects world-wide, where water availability is becoming a significant constraint on development.

This paper contributes to the literature on optimal natural resource use under uncertainty as exemplified by papers such as Pindyck (1980), Brennan and Schwartz (1985), Mason (2001), Slade (2001), and Chen and Insley (2012), and Insley (2017). It extends the analysis in these papers by including an uncertain regulatory constraint resulting from natural variability in the environment. It also contributes to the environmental economics literature addressing water issues specifically. A paper with a similar motivation is Mannix et al. (2014) which examines the efficiency of Alberta's water regulations for the oil sands using a deterministic model. We will contrast our conclusions to their results. Also of note are some papers addressing the optimal use of publicly owned water storage facilities in agricultural operations (Alaouze (1991), Brennan (2010), Dudley and Hearn (1993)).

As a preview, some key findings of the paper are summarized below.

- Phase 1 water regulations impose only a very small cost on our hypothetical oil sands firm. Costs only become significant under drier river conditions and more strict regulations than specified in the Alberta Framework.

- Oil price volatility affects the decision to invest in water storage facilities in an interesting way, depending on the extent to which water limitations are binding. When water withdrawals are highly restricted, an increase in price volatility makes the investment in storage more likely (i.e. the critical oil price for investment is reduced). In contrast, when water restrictions are not binding an increase in oil price volatility 
makes it optimal to delay investment in water storage. A change in oil price volatility may have a significant effect on the cost of water restrictions.

- Stricter regulations on water withdrawals may cause a firm to delay the permanent abandonment of a project.

- The marginal cost of water restrictions is lower when storage is in place and, as expected, rises as water restrictions are tightened. The shape of the marginal cost curve is affected by the option to install storage, and is non-monotonic when it becomes optimal to install storage.

The rest of this paper is structured as follows. Section 2 provides background information related to the oil sands industry and Alberta's water use regulations. Sections 3 and 4 develop a model for the stochastic optimal control problem. Section 5 describes the determination of parameter values in the model. Section 6 elaborates on the results. Section 7 reports on sensitivity analysis, while Section 8 concludes.

\section{Regulation of Water Use In the Alberta Oil Sands}

Open pit oil sands mining depends heavily on fresh water as an input, in contrast to in-situ projects which are able to use both saline and fresh water. Water requirements in barrels of water per barrel of oil are compared in Table 1.

\begin{tabular}{||c|c|c|c||}
\hline Water requirements for: & Minimum & Maximum & Average \\
\hline \hline Open-pit mining & 1.94 & 6.53 & 4.03 \\
In situ & 1.25 & 3.19 & 2.22 \\
\hline
\end{tabular}

Table 1: Water requirements, barrels of water per barrel of water. Converted from gallons/MMBtu assuming 7.2 gallons of oil are required to produce $1 \mathrm{MMBtu}$ of distillate number 2 fuel oil. Based on data in Kuwayama et al. (2013)

As noted in the Introduction, with the advent of the Framework, the FITFIR water allocation rule was supplanted by the requirement for firms to submit water sharing agreements 
annually to the government (Oil Sands Mining Water Management Agreements), which detailed how cumulative withdrawals would be shared within the terms of existing water licenses in event of a shortfall. The 2008-2009 agreement gave priority to those firms holding older licenses (Adamowicz et al., 2010). Subsequent agreements, at least since 2012, specify more equal sharing of the reductions in allowed water usage. Before 1999, licenses to withdraw water were issued without expiry dates according to the Water Resources Act. Since the Water Act took effect in 1999, new water licenses have a fixed time of validity (usually ten years). In practice, the amount of water permitted to be withdrawn by the licenses is more than enough to meet current production levels. Since the water allocated to the oil sands industry greatly exceeds the amount actually withdrawn, oil sands water users are not bound by licenses. Consequently, there arose some concerns about the impact of surface fresh water withdrawals on the aquatic ecosystem, should firms ever decide to make full use of the water they are licensed to use. According to Lunn et al. (2013), in the Lower Athabasca River, the collective withdrawals constitute only a tiny percentage of the river flow (less than $0.6 \%$ of average total river flows and about $3 \%$ of the lowest weekly winter flows). However, since the river flows vary significantly between seasons while the oil sands production has less seasonal variation, in water short seasons, there are risks that the withdrawals will exceed the sustainable level and damage aquatic habitat. Moreover, a decade ago forecasts pointed to ongoing increases in oil sands production, which resulted in significant concerns expressed about the impacts of water withdrawals on the aquatic ecosystem (National Energy Board, 2006; Griffiths and Woynillowicz, 2003; Jensen, 2010; Toman et al., 2008; Woynillowicz et al., 2005; Peters et al., 2013; Mannix et al., 2010; Ivanhoe Energy Inc., 2012). Combined with the conclusions drawn by some scholars (Wolfe et al., 2012; Schindler and Donahue, 2006; Squires et al., 2010; Wolfe et al., 2008; Bawden et al., 2014; Rasouli et al., 2013; Peters et al., 2013) that there is a declining trend of the river flow in the Athabasca catchment, concerns about impacts on the aquatic ecosystem was unsurprising. Note that the Peace-Athabasca Delta is a landscape of great ecological significance, located within one of Canada's 15 UNESCO World Heritage Sites. Its ecosystem is heavily dependent on the river flow level of the Athabasca River (Wolfe et al., 2012).

As noted in Section 1, according to the Phase 1 Framework (Alberta and Canada, 2007) river flows were classified into three conditions (green, yellow or red) based on the weekly river flow measurements. In the green zone, the water flow is regarded as abundant, and 
there is negligible impact of withdrawals on the aquatic ecosystem. In the yellow zone, the river flow is considered as low, and it is assumed that the aquatic ecosystem may experience stress from a $15 \%$ withdrawal. In the red zone, the river flow is regarded as too low for habitat health. There are different withdrawal limits for three different river flow conditions. In the green zone, up to $15 \%$ of instantaneous flow is allowed to be cumulatively withdrawn by the five oil sands firms. In the yellow zone, the maximum amount of water allowed to be withdrawn is $10 \%$ of the average of HDA $80^{7}$ and $\mathrm{Q} 95^{8}$. In the red zone, only a maximum $5.2 \%$ of the historical median flow in each week can be withdrawn. Figure 1 depicts average, minimum and maximum river flows in the Athabasca River since 1957 compared to the three regimes set by the Phase 1 Framework. It also shows the frequency with which river flows would be classified in the green, yellow or red zones over that 60 year period. It will be observed that the river did fall into the yellow or red zones with a significant frequency over this period.

In the short term, a firm might respond to any requests to curb water use by scaling back production. Over the longer term, if a firm expects more frequent or more severe restrictions, investing in water storage or searching for new technology to conserve water might be desirable. Imperial Oil's Kearn Lake project was the first to invest in water storage in order to eliminate the need to withdraw water from the river during low flow seasons. ${ }^{9}$ Constructing an on-site pond is one feasible choice. ${ }^{10}$ According to the Alberta Energy Regulator (AER) Oil Sands and Coal Exploration Application Guide ${ }^{11}$, operators require permission from the AER if there are changes to exploration or operation locations, which includes construction of on-site water storage facilities.

Currently, oil sands companies are complying with the water withdrawal limits via the implementation of the annually renewed voluntary agreement, Oil Sands Water Management

\footnotetext{
${ }^{7} \mathrm{HDA} 80$ is the river flow level corresponding to a habitat area level that is equalled or exceeded $80 \%$ of the time.

${ }^{8} \mathrm{Q} 95$ is the flow level that is equalled or exceeded $95 \%$ of the time.

${ }^{9}$ See page 19 of Imperial Oils 2012 summary annual report

${ }^{10}$ According to an on-line article from Suncor Energy Inc. entitled "Athabasca River water use: 5 things you need to know." http://osqar. suncor.com/2014/07/ athabasca-river-water-use-5-things-you-need-to-know.html(accessed on January 11, 2020)

${ }^{11}$ Oil Sands and Coal Exploration Application Guide. https://www.aer.ca/documents/manuals/ Manual008.pdf(accessed on January 11, 2020)
} 


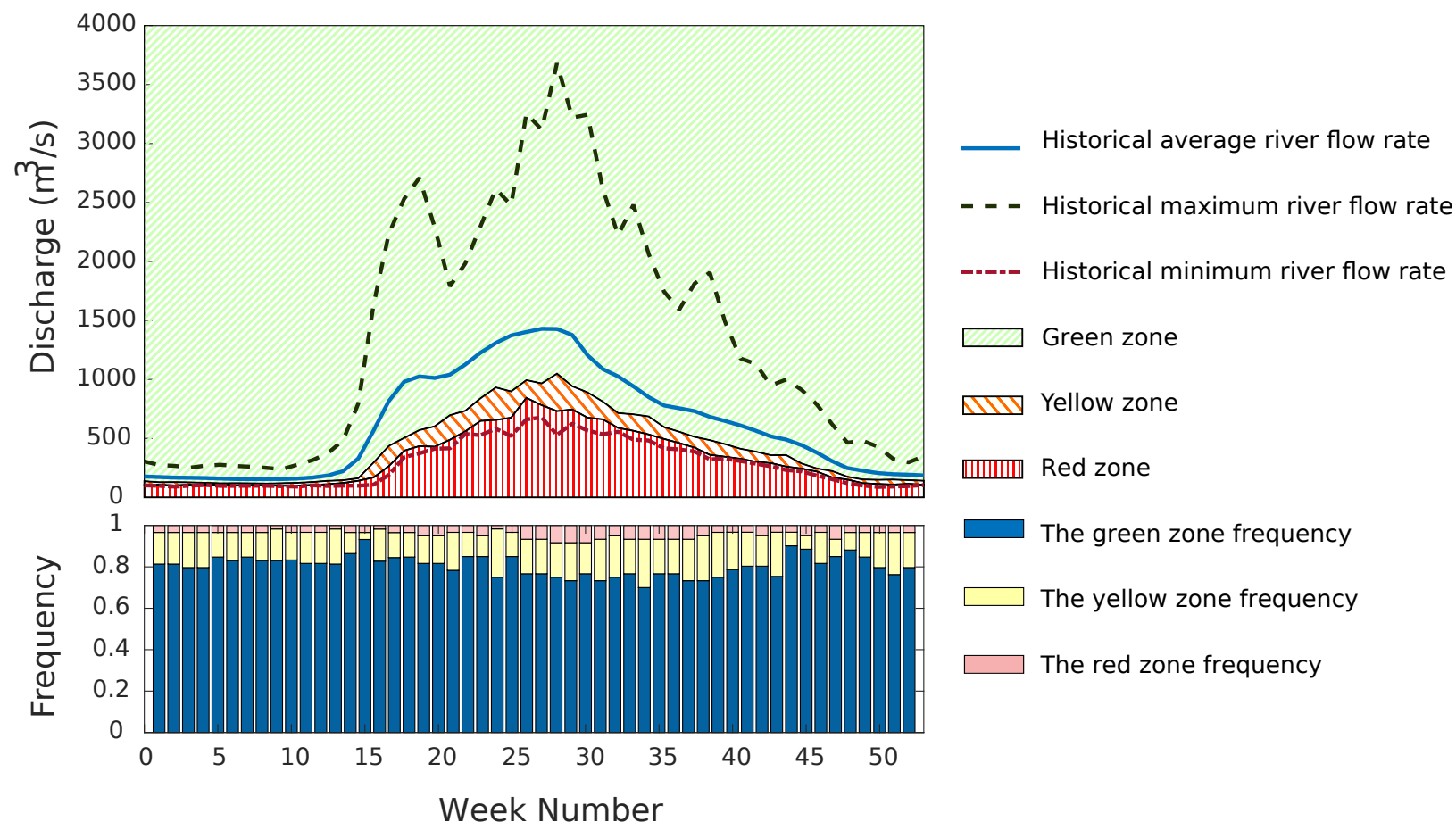

Figure 1: River Flows at the Athabasca River Gauge below Fort McMurray Station 07DA001 Compared to the Three Regimes Set by Alberta's 2007 Water Management Framework (The data are recorded from October 1, 1957 to December 31, 2017) 
Agreement for the Winter Period ${ }^{12}$ (herein after referred to as "the Agreement"). This agreement allocates the restricted water quantity almost equally among five oil sands extraction operators during the yellow and red zones. It stipulates that when the amount withdrawn by any individual operator exceeds the assigned allotment, the operator should report this to the relevant Alberta government department. However, there is no punishment specified for exceeding the agreed allotment. In the event that this agreement is not renewed we would expect water allocation to revert to the FITFIR principle.

The extent of inefficiencies of water allocation systems such as FITFIR, equal allocation, or riparian, in practice, has been the subject of debate (see, for example, Bennett et al. (2000), Libecap (2011); Libecap and Barbara (2012)). Barring a mechanism for water transfers, their efficiency will depend on the extent to which the rule for sharing in any cutback requires the largest curtailment from those with the lowest marginal value of water use (Weber and Cutlac, 2014). Efficiency will also depend critically on the protection given to in-stream river flows.

\section{Model description}

We analyze the case of a typical oil sands firm in the Lower Athabasca River region. We assume the operation is large enough that a single water storage pond will serve only one operation. Our goals are to determine the best timing for this firm to construct a water storage facility to maximize profits under the water restrictions set by the Framework as well as to explore the marginal cost of the restrictions for a typical firm. The decision model is based on the one developed in Insley (2017), however, the current model includes the constraint on water withdrawals which follows a Poisson process, includes water inventory as an additional state variable, and includes the decision to construct storage as an optimal control.

\footnotetext{
${ }^{12}$ For example: Oil Sands Water Management Agreement for the 2014-2015 Winter Period. http:// osip.alberta.ca/library/Dataset/Details/562(accessed on January 11, 2020)
} 


\subsection{Oil Production and Water Usage}

We assume that the firm is already producing bitumen from its oil sands development and that there is a fixed oil to water ratio. In practice this is a reasonable assumption as, given a certain technology choice, the ratio appears to be highly stable, based on data for average industry water use from 2003 to 2013. ${ }^{13}$ Accordingly, we assume a linear production function:

$$
Q\left(W_{p}(t), t\right)=\eta W_{p}(t) \quad \eta>0, W_{p}(t) \geqslant 0,0 \leq Q\left(W_{p}(t), t\right) \leq \bar{q}
$$

where $Q$ is output, $\eta$ is the number of barrels of bitumen that can be produced using one barrel of fresh water, $W_{p}(t)$ is the water used in production at time $t$, and $\bar{q}$ is a fixed upper limit on the rate of production. We assume that the production technology is stable so that $\eta$ is a constant independent of $t$.

With no water management regulations, the firm can produce up to its full capacity by using water without any restriction. In the presence of the Framework, in the absence of water storage capacity, the firm has to cut back production during the yellow and red zones, in which case profits will be impaired. To maintain its profitability, the firm will consider installing a water storage facility. The inventory of water in storage, $I$, will be augmented by water withdrawals from the river, $W_{w}$ and reduced by $W_{p}$ as water is drawn out of storage for use in oil production. The change in water inventory is given by the following differential equation:

$$
\mathrm{d} I=\left(W_{w}(t)-W_{p}(t)\right) \mathrm{d} t
$$

The level of the water inventory in storage is constrained to be a positive number which is less than the storage capacity $\bar{I}$ :

$$
I(t)=I\left(t_{0}\right)+\int_{t_{0}}^{t}\left(W_{w}\left(t^{\prime}\right)-W_{p}\left(t^{\prime}\right)\right) \mathrm{d} t^{\prime} \geqslant 0, \quad I\left(t_{0}\right)=I_{0}, \quad 0 \leq I(t) \leq \bar{I}
$$

\footnotetext{
${ }^{13}$ Net fresh water use in oil sands production from 2003 - 2013 averaged about 3.4 barrels of water per barrel of oil produced by mining operations and was stable from year to year. Source: Responsible Canadian Energy 2014 Progress Report, http://www.capp.ca/publications-and-statistics/ publications/(accessed on January 11, 2020)
} 


\subsection{Water Withdrawals From the River}

According to the Framework, a weekly constraint on fresh water withdrawals is set for the oil sands industry and the restricted cumulative withdrawal in the yellow and red conditions is allocated among five oil sands firms roughly evenly. ${ }^{14}$ The rate of water withdrawal, $W_{w}$, is restricted to be no greater than $\bar{W}$ where $\bar{W} \in\left\{\bar{W}_{1}, \bar{W}_{2}, \bar{W}_{3}\right\}$. The subscripts $k=1,2,3$, represent the river flow condition or water zone where $k=1$ is the green zone, $k=2$ is the yellow zone, and $k=3$ is the red zone. It is assumed that the change of water constraint from the current zone $k$ to another $u$ can be described by a stochastic differential equation.

$$
\mathrm{d} \bar{W}=\sum_{u=1}^{3}\left(\bar{W}_{u}(t)-\bar{W}_{k}(t)\right) \times \mathrm{d} X_{k \rightarrow u} \quad k=1,2,3
$$

where $\mathrm{d} X_{k \rightarrow u}$ is a Poisson Process:

$$
\mathrm{d} X_{k \rightarrow u}=\left\{\begin{array}{ll}
1 & \text { with probability }\left(\lambda^{k \rightarrow u} \mathrm{~d} t\right), \\
0 & \text { with probability }\left(1-\lambda^{k \rightarrow u} \mathrm{~d} t\right) .
\end{array} \quad k=1,2,3 ; u=1,2,3\right.
$$

The Poisson process is intended to reflect the natural variability in river flows. We assume that the risk of uncertain water flows is not correlated with the economy and the stock market. Therefore, it is a diversifiable risk and the real or $\mathcal{P}$ measure can be used to model $\mathrm{d} X .^{15}$

\subsection{Oil Resource Stock}

Production depletes the resource stock $S$ :

$$
\mathrm{d} S=-Q\left(W_{p}(t), t\right) \mathrm{d} t, S\left(t_{0}\right)=s_{0}
$$

\footnotetext{
${ }^{14}$ Each year the Agreement updates the assignment of water. Only the current year's Agreement is publicly available. This information was taken from the Agreement for the 2014-2015 winter period.

${ }^{15}$ See Geman (2005) for an introductory discussion of the real or $\mathcal{P}$ measure versus the risk neutral or $\mathcal{Q}$. Björk (2009) provides an advanced treatment.
} 
given

$$
\int_{t_{0}}^{T} Q\left(W_{p}(t), t\right) \mathrm{d} t \leq S\left(t_{0}\right)
$$

where $S\left(t_{0}\right)$ is the level of available oil reserves at $t_{0}, t_{0}$ is starting time, and $T$ is the lease end date.

\subsection{Project Stages}

To investigate the investment behaviour of this firm, we consider following 5 project stages. In the first stage, there is no water storage facility, and the firm holds the option to suspend production (stage 2) or to move on to stage 3, in which the water storage facility is installed and put into use. With the presence of the water storage facility, the firm can choose to stay in stage 3 , or suspend the production temporarily (stage 4). The final stage, stage 5 , is the permanent abandonment of the project. When in stages 1 to 4 , the firm can decide to abandon (switching to stage 5) by paying an abandonment cost. Let $\delta_{m}$ be the notation for each stage, where $m$ stands for the sequence number of stages and $m=1, \ldots, M$. In our case $M=5$. Stages are summarized in the following table:

\begin{tabular}{cl}
\hline Stage, $\delta$ & \multicolumn{1}{c}{ Description } \\
\hline 1 & Producing oil, no storage \\
2 & Suspended, no storage \\
3 & Producing oil, storage installed \\
4 & Suspended, storage installed \\
5 & Permanently abandoned \\
\hline
\end{tabular}

\subsection{Oil Prices}

There is a substantial existing literature examining alternative models for stochastic resource prices. Seminal papers include Brennan (1991), Gibson and Schwartz (1990), Schwartz (1997), and Schwartz and Smith (2000). The best model choice depends on the context in which it will be used. For this paper we desire a parsimonious model that provides a reasonable depiction of the behaviour of oil prices, but does not involve additional stochastic 
factors which unnecessarily complicate the solution of the HJB equation. Huang (2020), examined two single-regime mean-reverting process models and a two-regime mean-reverting process model to explore their performance in capturing the characteristics of oil price dynamics. The two-regime model performed the best overall, but the single regime logarithmic mean-reverting model also performs well. The analysis for this paper was done using both the single and two regime processes and the results were found to be qualitatively similar. We therefore present the results for the log mean-reverting model to avoid unnecessary complexity of two price regimes as well as three water zones.

The assumed stochastic differential equation describing oil prices under the Q-measure (i.e. the risk neutral measure)is given as follows:

$$
\mathrm{d} P=\epsilon(\mu-\ln P(t)) P(t) \mathrm{d} t+\sigma P(t) \mathrm{d} z
$$

where $P(t)$ is the crude oil spot price at time $t, \mu$ is the long run mean log price that $\ln P(t)$ tends to, $\epsilon$ is the speed of the mean reversion, $\sigma$ is the volatility, and $\mathrm{d} z$ is the increment of a Wiener process. $\epsilon(\mu-\ln P(t)) P(t)$ and $\sigma P(t)$ are called the drift term and the volatility term respectively. $\mathrm{d} z$ and $\mathrm{d} X_{k \rightarrow u}$ (defined in Equation (5)) are assumed to be independent of each other. ${ }^{16}$

\subsection{Cash Flows}

Annual cash flows are derived from revenue from the production and sale of oil reserves less fixed, variable costs and taxes. Both revenues and costs depend on the stage of operation, whether the project is operating, temporarily suspended or permanently abandoned. At time $t$, the realized profits will be:

\footnotetext{
${ }^{16}$ This assumption is justified because it is reasonable to treat oil price shocks and river flows as independent factors.
} 


$$
\begin{aligned}
& \pi(P(t), S(t), \bar{W}(t), I(t), \delta(t))= \\
& {\left[P(t) \cdot \rho-\left(c_{v_{e}}^{o}+c_{v_{n e}}^{o}\right) \cdot \mathbb{1}_{\{\delta=1,3\}}\right] \cdot \eta \cdot W_{p}(P(t), S(t), \bar{W}(t), I(t), \delta(t))} \\
& -c_{f}^{o} \cdot \mathbb{1}_{\{\delta=1,3\}}-c_{s} \cdot \mathbb{1}_{\{\delta=1,2,3,4\}}-\left[c_{f}^{s}+c_{v}^{s}(I)\right] \cdot \mathbb{1}_{\{\delta=3,4\}}-\Lambda(P(t), \delta(t)) \cdot \mathbb{1}_{\{\delta=1,2,3,4\}}
\end{aligned}
$$

where $\rho$ is the discount of bitumen prices against WTI prices. $\mathbb{1}_{\delta=\delta_{m}}$ is the indicator function which equals one if $\delta=\delta_{m}$ and zero otherwise. $c_{v_{e}}^{o}$ is the energy variable operating cost of oil production, $c_{v_{n e}}^{o}$ is the non-energy variable operating cost, $c_{f}^{o}$ is the fixed operating cost, $c_{s}$ is the sustaining capital cost no matter whether the operating is carried on or suspended, $c_{f}^{s}$ is the fixed cost of water storage, $c_{v}^{s}(I)$ is the variable cost of water storage, which depends on the water inventory $I$, and $\Lambda$ is the sum of all applicable taxes:

- Carbon tax $(\$ / \text { barrel })^{17}=$ Carbon tax rate $(\$ /$ tonne $) \times$ Carbon emissions $($ Tonnes $/$ barrel $)$;

- Royalty $(\$ /$ barrel $)=$ Royalty rate $^{18} \times P(t)(\$ /$ barrel $) \times \rho$;

- Income tax $(\$ /$ barrel $)=\max \{0$, Income tax rate $\times[P(t)(\$ /$ barrel $) \times \rho$ - Royalty $(\$ /$ barrel) - Carbon tax $(\$ /$ barrel $)$ - Operating cost $(\$ /$ barrel $)]\}$.

That is to say, $\Lambda(P(t), \delta(t))=$ carbon tax + royalty + income tax.

In addition to annual cash flows, there are one time costs incurred to move from one stage to another. To go from an operating stage without storage to one with storage, the cost of constructing storage facilities must be incurred, which we denote as $C$. To switch from an operating stage to a suspending stage, the mothball cost, $C_{m}$ is incurred. To move back from a suspending stage to an operating stage, the reactivating cost, $C_{r e}$ is incurred. Similarly, to move from any stage to permanent abandonment, an abandonment cost, $C_{r}$ is incurred. We also assume that it is not possible to move from a stage with water storage

\footnotetext{
${ }^{17}$ Unless otherwise specified in this paper, all references to "\$" or "dollars" herein refer to United States (U.S.) dollars.

${ }^{18}$ The royalty rate differs between the pre-payout and the post-payout phases of a project. Before the point that a project's cumulative revenues start to cover its cumulative costs, it is in the pre-payout phase. After this point, it is in the post-payout phase. Without altering the qualitative results of our research, we assume that the studied project is in the pre-payout phase.
} 
back to a stage without water storage or move from permanent abandonment back to any other stage. This is implemented by setting the costs to these relevant stage switches as a very large number $C_{\text {large }}$.

Table 2 summarizes the costs incurred in or between stages.

Table 2: Project Costs

\begin{tabular}{lccccc}
\hline & Stage 1 & Stage 2 & Stage 3 & Stage 4 & Stage 5 \\
\hline Annual costs & & & & & \\
Fixed operating cost $c_{f}^{o}$ & $\checkmark$ & & $\checkmark$ & & \\
Sustaining capital cost $c_{s}$ & $\checkmark$ & $\checkmark$ & $\checkmark$ & $\checkmark$ & \\
Energy variable operating cost $c_{v_{e}}^{o}$ & $\checkmark$ & & $\checkmark$ & & \\
Non-energy variable operating cost $c_{v_{e}}^{o}$ & $\checkmark$ & & $\checkmark$ & & \\
The fixed cost of water storage $c_{f}^{s}$ & & & $\checkmark$ & $\checkmark$ & \\
The variable cost of water storage $c_{v}^{s}(I)$ & & & $\checkmark$ & $\checkmark$ & \\
One time costs & & & $\checkmark$ & & \\
Construction $\operatorname{cost}$ of water storage $C$ & & $\checkmark$ & & $\checkmark$ & \\
Mothball cost $C_{m}$ & $\checkmark$ & & $\checkmark$ & & $\checkmark$ \\
Reactivating $\operatorname{cost} C_{r e}$ & & & & & $\checkmark$ \\
Abandonment $\operatorname{costs} C_{r}$ & & &
\end{tabular}

\section{Specification of the Decision Problem}

The firm's objective is to maximize the expected present value of cash flows from its oil sands operation over $T$ years. There are three control variables: water withdrawals $\left(W_{w}\right)$ from the river, oil production $Q$ (which determines the water used in production, $W_{p}$ ), and the decision to switch project stages which we denote $\left(\delta^{+}\right)$. Control variables depend on five state variables: the oil price $(P)$, the resource stock $(S)$, the water withdrawal limit $(\bar{W})$, the water inventory in storage $(I)$, and the current project stage $(\delta)$. 


\subsection{Admissible Sets for Control Variables}

Admissible sets are now specified for the control variables. Let $Z_{\delta^{+}}$denote the admissible set for $\delta^{+}$where

$$
Z_{\delta^{+}}=\left\{\delta_{1}, \delta_{2}, \delta_{3}, \delta_{4}, \delta_{5}\right\} .
$$

The admissible set for oil production, $Q$, depends on the resource stock, water storage inventory, project stage, and water withdrawals from the river. Denote this admissible set as $Z_{Q}\left(S, I, \delta, W_{w}\right)$, which is given as follows:

$$
\begin{aligned}
Q & \in Z_{Q}\left(S, I, \delta, W_{w}\right) \\
Z_{Q} & =\left[0, \min \left[S, \bar{q}, \eta W_{w}\right]\right], \text { if } S>0, \delta=\delta_{1} . \\
Z_{Q} & =\left[0, \min \left[S, \bar{q}, \eta\left(W_{w}+I\right)\right]\right], \quad \text { if } S>0, \delta=\delta_{3} . \\
Z_{Q} & =0, \quad \text { if } S=0, \delta=\delta_{m}, m=1,3 . \\
Z_{Q} & =0, \text { if } \delta=\delta_{m}, m=2,4,5, \forall S .
\end{aligned}
$$

Equation (11b) states that in stage $\delta_{1}$, oil production is constrained by the stock of oil reserves, the maximum oil production limit, and the amount of water withdrawn from the river multiplied by the water productivity coefficient. In stage 3, described in Equation (11c), water from the existing storage inventory is added to the current water withdrawal from the river as a constraint on water available for oil production.

Define an admissible set for water withdrawals, $W_{w}$, denoted $Z_{W}(\bar{W}, \delta)$, as follows:

$$
\begin{aligned}
W_{w} & \in Z_{W}(\bar{W}, \delta) \\
Z_{W} & =\left[0, \bar{W}_{1}\right], \quad \text { if } \quad \bar{W}=\bar{W}_{1}, \delta=\delta_{1}, \delta_{3} \\
Z_{W} & =\left[0, \bar{W}_{2}\right], \quad \text { if } \quad \bar{W}=\bar{W}_{2}, \delta=\delta_{1}, \delta_{3} \\
Z_{W} & =\left[0, \bar{W}_{3}\right], \quad \text { if } \quad \bar{W}=\bar{W}_{3}, \delta=\delta_{1}, \delta_{3} \\
Z_{W} & =0, \quad \text { if } \quad \delta=\delta_{2}, \delta_{4}, \delta_{5}
\end{aligned}
$$




\subsection{Optimal Controls and Value Function}

It is assumed that at predetermined, fixed times, the firm makes a decision about whether to change to a different project stage. These fixed times are denoted by $\mathcal{T}_{d}$ :

$$
\mathcal{T}_{d} \equiv\left\{t_{0}=0<t_{1}<\ldots<t_{m}<, \ldots, t_{M}=T-1\right\}
$$

The firm can switch stages instantaneously at $t \in \mathcal{T}_{d}$. At time $T$, the project must be terminated and clean up costs are incurred. In the numerical example in this paper, the time between fixed decisions dates is set as one week.

Choices regarding the rate of water withdrawal, $W_{w}$, and oil production, $Q$, are made in continuous time in time intervals given as follows:

$$
\mathcal{T}_{c} \equiv\left\{\left(t_{0}, t_{1}\right), \ldots,\left(t_{m-1}, t_{m}\right), \ldots,\left(t_{M-1}, t_{M}\right)\right\}
$$

Controls are specified as functions of state variables as follows:

$$
\begin{aligned}
& Q^{+}(P, S, \bar{W}, I, \delta, t), \quad W_{w}^{+}(P, S, \bar{W}, I, \delta, t), t \in \mathcal{T}_{c} \\
& \delta^{+}(P, S, \bar{W}, I, \delta, t), t \in \mathcal{T}_{d} .
\end{aligned}
$$

Let $K$ denote the set of particular choices for the controls for all $t_{m}$.

$$
K=\left\{\left(\delta^{+}\right)_{t \in \mathcal{T}_{d}} ;\left(Q^{+}, W_{w}^{+}\right)_{t \in \mathcal{T}_{c}}\right\}
$$

For any particular $K$, the value function $V(p, s, \bar{w}, \iota, \bar{\delta}, t)$, can be written as the expected discounted value of the integral of future cash flows with the expectation taken over the controls, given the state variables, where $p, s, \bar{w}, \iota, \bar{\delta}$ denote particular realizations of the state variables $P, S, \bar{W}, I$, and $\delta$. 


$$
\begin{gathered}
V(p, s, \bar{w}, \iota, \bar{\delta}, t)=\mathbb{E}_{K}\left[\int _ { t ^ { \prime } = t } ^ { t ^ { \prime } = T } e ^ { - r t ^ { \prime } } \pi \left(P\left(t^{\prime}\right), S\left(t^{\prime}\right), \bar{W}\left(t^{\prime}\right), I\left(t^{\prime}\right),\left(\delta\left(t^{\prime}\right)\right) d t^{\prime}\right.\right. \\
+e^{-r(T-t)} V(P(T), S(T), \bar{W}(T), I(T), \delta(T), T) \\
\mid P(t)=p, S(t)=s, \bar{W}(t)=\bar{w}, I(t)=\iota, \delta(t)=\bar{\delta}] .
\end{gathered}
$$

$r$ is the risk free interest rate, which is assumed to be 0.02 , and $\mathbb{E}[\cdot]$ is the expectation operator. Note that the expectation is taken under the risk neutral or $\mathcal{Q}$ measure. In our numerical example the value in the final time period, $V(P(T), S(T), \bar{W}(T), I(T), \delta(T), T)$, is assumed to be the cost of clean up if the project had not been abandoned before $T$ $\left(\delta=\delta_{m}, \quad m=1,2,3,4\right)$, or is equal to zero if the firm has already abandoned the project $\left(\delta=\delta_{5}\right)$.

Equation (16) is solved for the optimal controls contained in the admissible sets (Equations (10), (11), and (12) and subject to Equations for $\mathrm{d} S, \mathrm{~d} \bar{W}, \mathrm{~d} I$, and $\mathrm{d} P((6),(4),(2)$, and (8)). A dynamic programming algorithm is implemented solving backwards in time and proceeding in two phases: (1) the decision to switch stages made at fixed time points, $t_{m}$, and (2) the choice of water withdrawals and oil production made in continuous time in the interval $t \in\left(t_{m}^{+}, t_{m+1}^{-}\right)$, where $t_{m}^{+}$denotes the instant after $t_{m}$ and $t_{m+1}^{-}$denotes the instant before time $t_{m+1}$.

\subsection{Solution at Fixed Decision Dates}

At any $t_{m} \in \mathcal{T}_{d}$, the decision on the optimal stage from $t_{m}^{+}$should be the one in which the project value minus switching cost is the maximum, other things equal.

$$
\delta^{+}\left(p, s, \bar{w}, \iota, \bar{\delta}, t_{m}\right)=\underset{\delta}{\arg \max }\left(V\left(p, s, \bar{w}, \iota, \delta, t_{m}\right)-C_{\bar{\delta} \rightarrow \delta}\right)
$$

where $C_{\bar{\delta} \rightarrow \delta}$ denotes the cost for switching from stage $\bar{\delta}$ at time $t_{m}$ to stage $\delta$ at time $t_{m}^{+}$. Table 3 specifies $C_{\bar{\delta} \rightarrow \delta}$ at the intersection of $\bar{\delta}^{\text {th }}$ row and the $\delta^{\text {th }}$ column. 
Table 3: Switching Costs

\begin{tabular}{clllll}
\hline Stage & 1 & 2 & 3 & 4 & 5 \\
\hline 1 & 0 & $C_{m}$ & $C$ & $C_{\text {large }}$ & $C_{r}$ \\
2 & $C_{r e}$ & 0 & $C_{\text {large }}$ & $C_{\text {large }}$ & $C_{r}$ \\
3 & $C_{\text {large }}$ & $C_{\text {large }}$ & 0 & $C_{m}$ & $C_{r}$ \\
4 & $C_{\text {large }}$ & $C_{\text {large }}$ & $C_{r e}$ & 0 & $C_{r}$ \\
5 & $C_{\text {large }}$ & $C_{\text {large }}$ & $C_{\text {large }}$ & $C_{\text {large }}$ & 0 \\
\hline
\end{tabular}

\subsection{Solution between Fixed Decision Dates, Going Backward In Time From $t_{m+1}^{-}$to $t_{m}^{+}$.}

In this section we describe the solution going backwards in time between decision dates, i.e. $t_{m+1}^{-} \rightarrow t_{m}^{+}$. Define the differential operator $\mathcal{L}$ as follows:

$$
\begin{aligned}
& \mathcal{L} V= \\
& \frac{1}{2} b^{2} \frac{\partial^{2} V}{\partial P^{2}}+a \frac{\partial V}{\partial P}-Q \frac{\partial V}{\partial S}+\left(W_{w}-W_{p}\right) \frac{\partial V}{\partial I}+\sum_{u=1, u \neq k}^{3} \lambda^{k \rightarrow u}\left(V\left(\bar{w}=\bar{W}_{u}\right)-V\left(\bar{w}=\bar{W}_{k}\right)\right)-r V
\end{aligned}
$$

where $a \equiv \epsilon(\mu-\ln P) P ; \quad$ and $\quad b \equiv \sigma P$.

Recall that there is a fixed relationship between water used in production, $W_{p}$, and the rate of oil production $W_{p}=Q / \eta$.

Define a small time interval $h$ where $h<\left(t_{m+1}-t_{m}\right)$. For $t \in\left(t_{m}^{+}, t_{m+1}^{-}-h\right)$, according to the dynamic programming principle, for small $h$ we know that

$$
\begin{gathered}
V(p, s, \bar{w}, \iota, \bar{\delta}, t)=e^{-r h} \mathbb{E}[V(P(t+h), S(t+h), \bar{W}(t+h), I(t+h), \delta(t),(t+h)) \mid \\
P(t)=p, S(t)=s, \bar{W}(t)=\bar{w}, I(t)=\iota, \delta(t)=\bar{\delta}]
\end{gathered}
$$


Letting $h \rightarrow 0$ and applying Ito's Lemma ${ }^{19}$, the value function can be shown to satisfy the following Hamilton-Jacobi-Bellman equation:

$$
\frac{\partial V}{\partial t}+\pi(p, s, \bar{w}, \iota, \bar{\delta}, t)+\max _{Q, W_{w}}(\mathcal{L} V)=0
$$

Equation (21) is defined on the domain $(p, s, \bar{w}, \iota, \bar{\delta}, t) \in \Omega^{\infty}$, where

$$
\begin{aligned}
& \Omega^{\infty} \equiv[0, \infty] \times\left[0, S_{0}\right] \times Z_{\bar{W}} \times\left[0, I^{\max }\right] \times Z_{\delta} \times[0, T] \\
& Z_{\bar{W}}=\left\{\bar{W}_{1}, \bar{W}_{2}, \bar{W}_{3}\right\} \\
& Z_{\delta}=\left\{\delta_{1}, \delta_{2}, \delta_{3}, \delta_{4}, \delta_{5}\right\}
\end{aligned}
$$

$T$ reflects the length of the lease to operate the project. For computational purposes the domain $\Omega^{\infty}$ is truncated to $\Omega$ where

$$
\Omega \equiv\left[0, p_{\max }\right] \times\left[0, S_{0}\right] \times Z_{\bar{W}} \times\left[0, I^{\max }\right] \times Z_{\delta} \times[0, T] .
$$

$p_{\max }$ is chosen to be large enough to represent a very high oil price in relation to historical prices.

Boundary conditions are elaborated in Appendix A. Details of the numerical solution are briefy discussed in Appendix B.

\section{$5 \quad$ Specification of the Parameters}

\subsection{Oil Price Process, Bitumen Discount, and the Risk Free Rate}

Equation (8) was estimated in the risk neutral measure using futures contract prices on West Texas Intermediate crude oil. Data used was for contracts of less than one month to 17 months, from January 1995 to December 2016. The data were deflated by the U.S. consumer price index so that Equation (8) describes real oil prices. The details of the estimation procedure are described in (Huang, 2020). The estimates obtained are $\epsilon=0.14$,

\footnotetext{
${ }^{19}$ See Björk (2009) for a rigorous overview of optimal decisions under uncertainty characterized by an Ito process in a finance context. Dixit and Pindyck (1994) provides an introductory overview
} 
$\mu=4.59, \sigma=0.31$. Accordingly, the stochastic differential equation followed by oil prices is given as:

$$
\mathrm{d} P=0.14(4.59-\ln P) P \mathrm{~d} t+0.31 P \mathrm{~d} z .
$$

This estimated model provides a good description of the data with in-sample forecast errors of futures prices ranging from $0.6 \%$ to $1.6 \%$ depending on the contract length (Huang, 2020). Figure 2(a) shows the mean, median, and fifth and 95th percentiles for 100,000 simulations of the price model assuming an initial starting price of $\$ 80$ per barrel. We observe a wide range between the 5th and 95th percentiles, which reflects the quite large volatility term. Recall that this is in the risk neutral measure so it reflects a risk premium demanded by market participants to invest in oil linked assets. For reference, historical WTI prices since 2007, deflated by the U.S. CPI are shown in Figure 2(b).
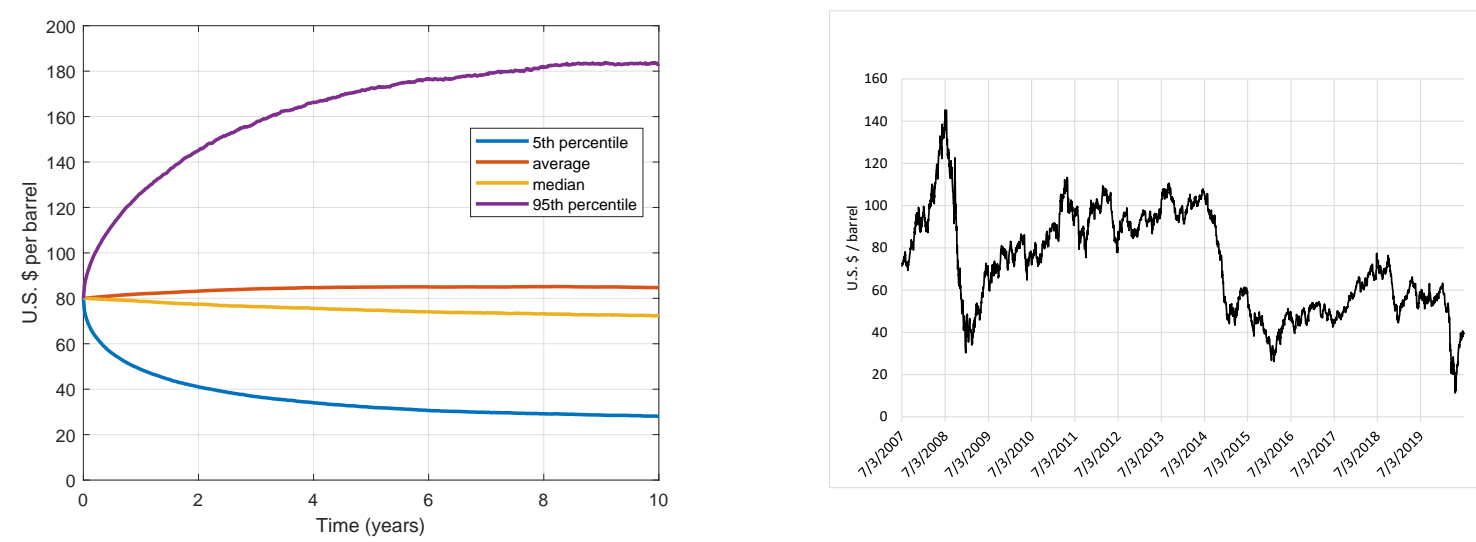

(a) Simulation of real (2016\$) oil prices, Q-measure (b) Daily real (2020\$) WTI crude spot prices, July (Equation (23)), 10000 price realizations 2007 - July 2020

Figure 2: Simulated and historical real oil prices. Source of historical data: Macrotrends, Historical Oil Prices

With regard to the discount of bitumen prices against WTI prices, $\rho$ (see Equation (9)), as in Insley (2017), we fix it at the level of $83 \%$. In other words, we fix the oil sands price in Canadian dollars at $83 \%$ of the WTI price in US dollars. In reality, the bitumen price discount is highly variable and could itself be modelled as a second stochastic factor.

The risk free interest rate is set at 2 percent. 


\subsection{Water Withdrawal Limits}

The Framework sets the rules for determining these water withdrawal limits in different zones, and also explicitly lists for each week how many cubic meters of water per second the oil sands industry are permitted remove from the Athabasca River in the yellow and red zones based on the historical flow record up to 2007. The 'Alberta Oil Sands Industry Quarterly Update' (spring 2015) Economic Development and Trade (2015) (hereinafter referred to as "AOSIQU") shows that as of spring 2015 there were 12 surface mining projects in operation. Assuming the available water during the yellow and red zones is allocated evenly among those projects, according to the Framework, the resulting specific weekly water restrictions in the yellow and red zones for the whole industry and the amount assigned to each project are listed in Table 4. The weekly water limits in the yellow and red zones for the entire oil sands industry are also depicted in Figure 3. According to the AOSIQU, the total production capacity of the the oil sands mining sector was 9.975 million barrels/week, implying average production capacity at about 0.83 million barrels/week. If production is at full capacity, the weekly water required is about 33.3 million barrels. ${ }^{20}$ From Table 4 , it is shown that even if the river flow condition is in the yellow or the red zone, the total industry production would not be bound by the constraints. That said, we know that projects do differ in terms of their water demands and licenses so that when the river is in the red or yellow zone, some projects with less generous license provisions may experience water shortage. From the AOSIQU we know that in fact there are 4 of the existing 12 projects whose production may be restricted in yellow or red zones ( 2 of which cannot achieve the full capacity of production in the yellow zone.) In this case the water sharing agreement would apply so that those firms with more generous licenses would need to give up some of their water to share with firms in short supply. Or if the water sharing agreement was not renewed the FITFIR allocation would be reinstated. It might also be anticipated that the restrictions would be increasingly binding in the future if the industry grows (which does not appear likely from the perspective of 2020) or if river flows become less abundant over time. The Framework was developed in the context of a rapidly growing industry. For the purposes of this paper, we assume parameters for a hypothetical oil sands plant which is constrained by the water restrictions. Specifically

${ }^{20}$ This amount of water required is derived by using the water productivity specified in Section 5.3, page 25: 9.975 million barrels of bitumen/week $\times 3.34$ barrels of water/barrel of bitumen $=33.3$ million barrels of water/week. 
we consider a hypothetical project with a production capacity of 1.38 million barrels/week. If there were 12 equally sized projects this implies oil production capacity of 16.62 million barrels/week. Then the weekly water needed would be about 55.5 million barrels. In this hypothetical case, the water constraint due to the framework would be binding in some dry periods.

Table 4: Water Withdrawal Limit (million Barrels/week)

\begin{tabular}{|c|c|c|c|c|c|c|c|c|c|c|c|c|c|}
\hline Week & 1 & 2 & 3 & 4 & 5 & 6 & 7 & 8 & 9 & 10 & 11 & 12 & 13 \\
\hline Total (yellow zone) & 58.1 & 58.1 & 53.2 & 58.1 & 58.1 & 53.2 & 53.2 & 53.2 & 53.2 & 53.2 & 53.2 & 58.1 & 62.9 \\
\hline Total (red zone) & 48.4 & 43.5 & 43.5 & 43.5 & 43.5 & 38.7 & 38.7 & 38.7 & 38.7 & 38.7 & 38.7 & 43.5 & 43.5 \\
\hline Individual project (yellow zone) & 4.8 & 4.8 & 4.4 & 4.8 & 4.8 & 4.4 & 4.4 & 4.4 & 4.4 & 4.4 & 4.4 & 4.8 & 5.2 \\
\hline Individual project (red zone) & 4 & 3.6 & 3.6 & 3.6 & 3.6 & 3.2 & 3.2 & 3.2 & 3.2 & 3.2 & 3.2 & 3.6 & 3.6 \\
\hline Week & 14 & 15 & 16 & 17 & 18 & 19 & 20 & 21 & 22 & 23 & 24 & 25 & 26 \\
\hline Total (yellow zone) & 62.9 & 72.6 & 72.6 & 106.4 & 121 & 135.5 & 145.2 & 164.5 & 164.5 & 164.5 & 164.5 & 164.5 & 164.5 \\
\hline Total (red zone) & 48.4 & 62.9 & 72.6 & 106.4 & 121 & 135.5 & 145.2 & 164.5 & 164.5 & 164.5 & 164.5 & 164.5 & 164.5 \\
\hline Individual project (yellow zone) & 5.2 & 6 & 6 & 8.9 & 10.1 & 11.3 & 12.1 & 13.7 & 13.7 & 13.7 & 13.7 & 13.7 & 13.7 \\
\hline Individual project (red zone) & 4 & 5.2 & 6 & 8.9 & 10.1 & 11.3 & 12.1 & 13.7 & 13.7 & 13.7 & 13.7 & 13.7 & 13.7 \\
\hline Week & 27 & 28 & 29 & 30 & 31 & 32 & 33 & 34 & 35 & 36 & 37 & 38 & 39 \\
\hline Total (yellow zone) & 164.5 & 164.5 & 164.5 & 164.5 & 164.5 & 164.5 & 164.5 & 164.5 & 164.5 & 164.5 & 164.5 & 164.5 & 159.7 \\
\hline Total (red zone) & 164.5 & 164.5 & 164.5 & 164.5 & 164.5 & 164.5 & 164.5 & 164.5 & 164.5 & 164.5 & 164.5 & 164.5 & 159.7 \\
\hline Individual project (yellow zone) & 13.7 & 13.7 & 13.7 & 13.7 & 13.7 & 13.7 & 13.7 & 13.7 & 13.7 & 13.7 & 13.7 & 13.7 & 13.3 \\
\hline Individual project (red zone) & 13.7 & 13.7 & 13.7 & 13.7 & 13.7 & 13.7 & 13.7 & 13.7 & 13.7 & 13.7 & 13.7 & 13.7 & 13.3 \\
\hline Week & 40 & 41 & 42 & 43 & 44 & 45 & 46 & 47 & 48 & 49 & 50 & 51 & 52 \\
\hline Total (yellow zone) & 154.8 & 150 & 135.5 & 130.6 & 72.6 & 72.6 & 72.6 & 72.6 & 67.7 & 67.7 & 62.9 & 62.9 & 62.9 \\
\hline Total (red zone) & 154.8 & 150 & 135.5 & 130.6 & 72.6 & 72.6 & 72.6 & 58.1 & 53.2 & 48.4 & 48.4 & 48.4 & 48.4 \\
\hline Individual project (yellow zone) & 12.9 & 12.5 & 11.3 & 10.9 & 6 & 6 & 6 & 6 & 5.6 & 5.6 & 5.6 & 5.6 & 5.6 \\
\hline Individual project (red zone) & 12.9 & 12.5 & 11.3 & 10.9 & 6 & 6 & 6 & 4.8 & 4.4 & 4 & 4 & 4 & 4 \\
\hline
\end{tabular}

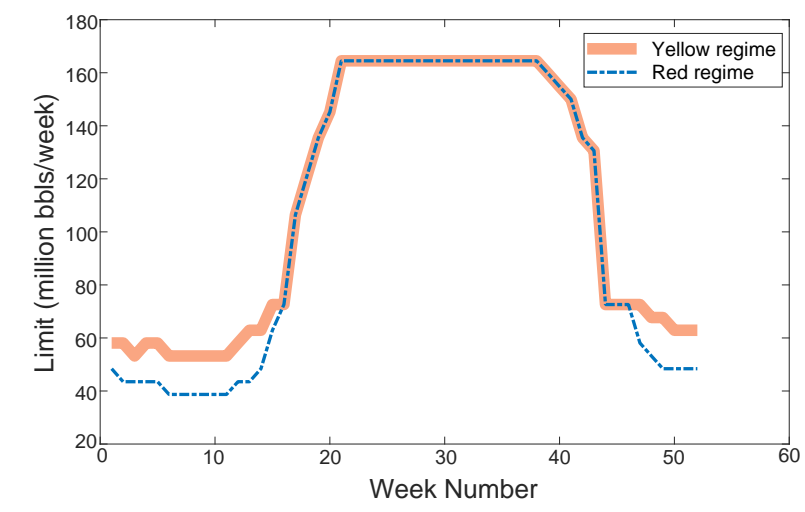

Figure 3: Weekly water withdrawal limits in the yellow and red zones 
The parameter $\lambda^{k \rightarrow u} \mathrm{~d} t$ in Equation (5) refers to the hazard rate of switching from river flow zone $k$ to $u$ in the period of $\mathrm{d} t$. We examined the historical data of Athabasca river flows and found that in the recent years the river flows are lower compared to the average historical level. For illustrative purposes, we adopt the relatively low river flows condition of 2015 for estimating the hazard rates. According to the 2015 data of Athabasca river flows provided by Alberta Environment, we estimate average values for $\lambda^{i \rightarrow j}$ (for all $i=1,2,3$ and $j=1,2,3$, where 1 corresponds to the green zone, 2 the yellow zone, and 3 the red zone.) as follows:

$$
\lambda^{i \rightarrow j}=\frac{N_{i \rightarrow j}}{N_{i}} \cdot \frac{1}{\mathrm{~d} t}
$$

where $N_{i}$ is the number of weeks in 2015 that are in the zone specified by $i, N_{i \rightarrow j}$ is the number of times that the zone switches from $i$ to $j$ in 2015, and $\mathrm{d} t$ is $\frac{1}{52}$ of a year or 1 week. The hazard rate matrix is as follows.

$$
\left[\begin{array}{ccc}
40.7 & 11.3 & 0 \\
12.2 & 36.7 & 3.1 \\
0 & 4.3 & 47.7
\end{array}\right]
$$

where the entry at the $\mathrm{i}^{\text {th }}$ row and the $\mathrm{j}^{\text {th }}$ column stands for $\lambda^{i \rightarrow j}$.

\subsection{Production Related Parameters}

We assume that the project is already in operation and the remaining lifespan is 10 years. Water requirements per barrel for each year are provided in the Responsible Canadian Energy 2014 Progress Report ${ }^{21}$ by the Canadian Association of Petroleum Producers. Herein we adopt the average level of fresh water withdrawal per barrel of production during the period of $2003 \sim 2013$, i.e. 3.34 barrels of water/barrel of oil. Therefore, $\eta=1 / 3.34 \approx 0.3$.

Section 5.2 (Table 4) shows that in the driest week (the $10^{\text {th }}$ week) of each year, the limitation in water availability confines a project's production to a maximum of 1.32 million

\footnotetext{
${ }^{21}$ Source: information provided on the website of Canadian Association of Petroleum Producers (CAPP) (http://www.capp.ca/publications-and-statistics/publications) (accessed on January 11, 2020).
} 
barrels of oil per week ${ }^{22}$ in the yellow zone and 0.96 million barrels/week ${ }^{23}$ in the red zone. As noted in the previous section we choose a hypothetical oil sands project with a production capacity of 1.38 million barrels/week so that the production is affected by both the yellow and red zones.

Information on water storage capacity was obtained from Imperial Oil's description of their Kearl oil sands project which commenced production on April 27, 201324. Like the Kearl project it is assumed that storage can sustain 30 days' production during the dry season, which implies a capacity of about 20 million barrels. A report of Golder Associates Ltd. (2015) showed that the capital cost for fresh water storage is $\$ 16 / \mathrm{m}^{3}$ and the annual operating costs for the storage is $5 \%$ of capital cost plus relevant power costs. Accordingly we assume that the storage facility in our case costs 39 million dollars and the fixed cost of running the facility is 2.1 million dollars/year. In the absence of publicly available information, it is assumed that the variable cost of operating the storage capacity is $\$ 0.0028 /$ barrel. It is further assumed that the construction of the storage pond can be accomplished instantly, an assumption which was found to have little effect on results.

We require an estimate of the remaining reserves of the hypothetical project. Given the above assumed production capacity of 1.38 million barrels/week (i.e. 72 million barrels/year), and the assumed 10-year project life, the upper limit of resource stock that a 10-year life project would extract is 720 million barrels if operating at full capacity. Therefore we assume the remaining resource stock for the hypothetical project is 720 million barrels. The hypothetical project's scale, in term of its production capacity and the remaining established reserves, is quite close to that of North Steepbank Extension project of Suncor Energy Inc.

With regard to the various cost values for operation, we used estimates provided by the Canadian Energy Research Institute (hereinafter referred to as "CERI") (Millington and Murillo (2015)) appropriately scaled for the size of our project. Table 2 details when the various costs are incurred. Table 5 lists all necessary parameter values for the hypothetical project in the base case.

\footnotetext{
${ }^{22}$ Each week the maximum amount of available water is 4.4 million barrels. Considering that 3.34 barrels of water can produce one barrel of oil, the weekly oil production is under 4.4/3.34 million barrels.

${ }^{23}$ Similarly derived by 3.2 million barrels $/ 3.34$

${ }^{24}$ Source: information provided on the website of Imperial Oil (http://www.imperialoil.ca/ Canada-English/operations_sands_kearl_environment.aspx) (accessed on January 11, 2020).
} 
Table 5: Base Case Parameter Values

\begin{tabular}{|c|c|c|c|c|}
\hline Parameter & Description & Reference & Assigned Value & Source \\
\hline & Extraction method & & Surface mining & $* * *$ \\
\hline$T-t_{0}$ & Remaining lifespan of the project (years) & Equation (7) & 10 & * \\
\hline $\bar{q}$ & Production capacity (million barrels/year) & Equation (1) & 72 & * \\
\hline$s_{0}$ & Remaining established reserves (million barrels) & Equation (7) & 720 & * \\
\hline$\eta$ & Productivity of water (barrels of bitumen/barrel of water) & Equation (1) & 0.3 & ** \\
\hline $\bar{W}_{1}$ & $\begin{array}{l}\text { Water withdrawal constraint in the green zone (million } \\
\text { barrels/week) }\end{array}$ & Equation (4) & $+\infty$ & $* * *$ \\
\hline $\bar{W}_{2}, \bar{W}_{3}$ & $\begin{array}{l}\text { Water withdrawal constraint in the yellow zone and } \\
\text { the red zone (million barrels/week) }\end{array}$ & Equation (4) & refer to Table 4 & * \\
\hline$\rho$ & Discount of bitumen prices against WTI prices & Equation (9) & $83 \%$ & * \\
\hline$C$ & $\begin{array}{l}\text { The construction cost of the water storage (million } \\
\text { dollars) }\end{array}$ & Table 2 & 39 & * \\
\hline $\bar{I}$ & Water storage capacity (million barrels) & Equation (3) & 20 & * \\
\hline$c_{f}^{s}$ & The fixed cost of water storage (million $\$ /$ year) & Equation (9) & 2.1 & $*$ \\
\hline \multirow[t]{2}{*}{$c_{v}^{s}$} & The variable cost of water storage $(\$ /$ barrel $)$ & Equation (9) & 0.0028 & $*$ \\
\hline & Carbon emissions (tonnes/barrel) & Equation (9) & 0.091 & $* *$ \\
\hline$c_{v_{e}}^{o}$ & Energy variable operating cost (\% of the WTI price) & Equation (9) & 1.62 & $* *$ \\
\hline$c_{v_{n e}}^{o}$ & Non-energy variable operating cost $(\$ /$ barrel $)$ & Equation (9) & 7.98 & $* *$ \\
\hline$c_{f}^{o}$ & Fixed operating cost (million $\$ /$ year) & Equation (9) & 470 & $* *$ \\
\hline \multirow[t]{4}{*}{$c_{s}$} & Sustaining capital cost (million $\$ /$ year) & Equation (9) & 468 & $* * *$ \\
\hline & Income tax rate $(\%)$ & Equation (9) & 25 & $* * *$ \\
\hline & Carbon tax (\$/tonne) & Equation (9) & 40 & $* * *$ \\
\hline & Royalty rate $(\%)$ & Equation (9) & $\begin{array}{l}1 \text { when } P<\$ 55 / \text { barrel } \\
9 \text { when } P>\$ 120 / \text { barrel } \\
(0.12 P-5.77) \text { otherwise }\end{array}$ & $* * *$ \\
\hline$C_{m}$ & Mothball cost (million $\$)$ & Table 2 & 0 & $*$ \\
\hline$C_{r e}$ & Reactivating cost (million $\$)$ & Table 2 & 0 & * \\
\hline$C_{\text {large }}$ & A large number to prevent stage switching (million $\$$ ) & Page 16 & $10^{9}$ & $*$ \\
\hline$C_{r}$ & $\begin{array}{l}\text { Abandonment cost (million } \$)(2 \% \text { of original capital } \\
\text { costs assumed to be } \$ 13.9 \text { billion) }\end{array}$ & Table 2 & 278 & * \\
\hline$\epsilon$ & Speed of reverting to the mean log oil price & Equation (8) & 0.14 & $* * *$ \\
\hline$\mu$ & Long run mean log oil price & Equation (8) & 4.59 & $* * *$ \\
\hline$\sigma$ & Volatility of oil prices & Equation (8) & 0.31 & $* * *$ \\
\hline $\begin{array}{l}\lambda^{1 \rightarrow 2} \\
\lambda^{1 \rightarrow 3} \\
\lambda^{2 \rightarrow 1} \\
\lambda^{2 \rightarrow 3} \\
\lambda^{3 \rightarrow 1} \\
\lambda^{3 \rightarrow 2} \\
\end{array}$ & $\begin{array}{l}\text { Hazard rate of switching } \\
\text { from the green zone to the yellow zone, } \\
\text { from the green zone to the red zone, } \\
\text { from the yellow zone to the green zone, } \\
\text { from the yellow zone to the red zone, } \\
\text { from the red zone to the green zone, } \\
\text { and from the red zone to the yellow zone }\end{array}$ & Equation (5) & $\begin{array}{l}11.3 \\
0 \\
12.2 \\
3.1 \\
0 \\
4.3 \\
\end{array}$ & $* * *$ \\
\hline$r$ & Risk free interest rate & Equation (16) & 0.02 & * \\
\hline
\end{tabular}

Source column: $* * *$ means these values are publicly available or are estimated from empirical evidence. $* *$ means these values are derived according to AOSIQU, Alberta Energy Regulator (2015), or CERI's report ((Millington and Murillo, 2015) . * means these values are assumed by referring to miscellaneous sources, which are specified in the text. 


\section{Results}

We examined four different scenarios which reflect current regulations and river conditions, as well as stricter regulations and drier river conditions. We denote these scenarios as follows.

- W_L (wet lenient scenario): The river flow is in the current condition (i.e. a fairly wet condition), as shown by the solid curve in Figure $4 .{ }^{25}$ The water withdrawal limit is regulated by the Phase 1 Framework, which is relatively lenient compared to the other case we examine.

- W_S (wet strict scenario): The river flow is in the current condition. The water withdrawal limit is tightened by 1.35 million barrels/week (i.e. up to $30 \%$ and $42 \%$ of the weekly withdrawal limit set by the Phase 1 Framework for the yellow zone and the red zone respectively)

- D_L (dry lenient scenario): The river flow is in such a dry condition that it falls in the red zone all the time, as shown by the dash-dot curve in Figure 4. The water withdrawal limit is regulated by the Phase 1 Framework.

- D_S (dry strict scenario): The river flow is in the red zone all the time. The water withdrawal limit is tightened by 1.35 million barrels/week based on the Phase 1 Framework which amounts to a $30 \%$ to $42 \%$ reduction in allowed water withdrawals over the year compared to the more lenient regulations of the Phase 1 Framework.

Figure 4 shows the levels of the weekly river flow rates for the wet (represented by "W" in the scenario nomenclature) and dry (represented by " $D$ " in the scenario nomenclature) river flow conditions compared to the historical river flow rates. The boxplots in Figure 4 indicate the first quartile (represented by the lower edge of each box), the third quartile (the upper edge of each box), the median (the short horizontal bar cutting through each box), the maximum level (the highest tip of the dashed whisker), the minimum level (the lowest tip of the dashed whisker), and outliers (the plus signs) of the historical weekly river flow rate.

\footnotetext{
${ }^{25}$ We call this scenario "wet" because it is relatively wet compared to other scenarios listed herein. It does not mean that it is in the wet spectrum of the historical river flow record. In fact, from Figure 4, we can see that this scenario is fairly dry if we use the historical record as a reference.
} 


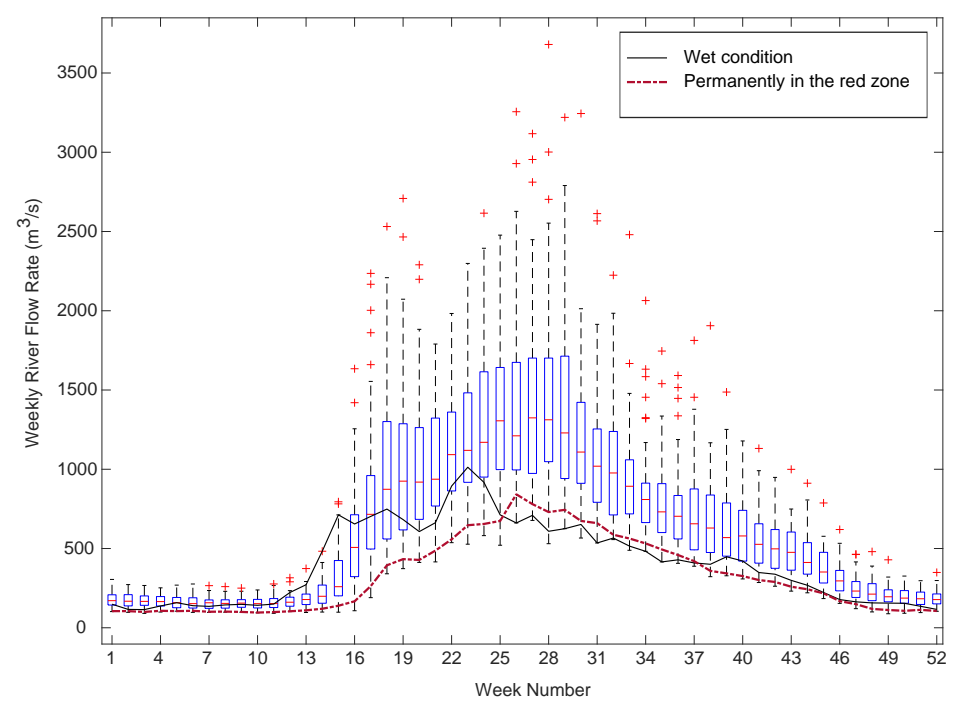

Figure 4: Curves Showing the Assumed Wet and Dry Weekly River Flow Rates versus the Box Plots of Historical Weekly River Flow Rates.

\subsection{Economic Impact of Water Restrictions for the Firm With No Storage Option}

In this section we examine the impact of the regulation on the oil sands project when there is no action or technology available to alleviate the water shortages, i.e. there is no storage option available. This case indicates the maximum effect of the water restrictions. Note also that a reliance on water storage to alleviate water shortfall has been the subject of controversy in certain cases due to potential negative environmental consequences as discussed in Di Baldassarre et al. (2018).

\subsubsection{Solution Surface for the Value of the Project}

Figure 5 depicts the solution surface for $W_{-}$L, which shows the project's values corresponding to different combinations of the oil sands resource stock and crude oil price when the present river flow condition is in the green zone. Note that this graph depicts the value of the project at time zero for different values of the state variables, assuming the project owner acts optimally in the choice of controls until the lease end date at time $T$. As expected, other things equal, the project's value rises with an increase in oil price as well as with an increase in resource stock. When the present river flow condition is in either of the other 
zones, the shape of the solution surface is very similar to that in Figure 5, and hence is not shown. For any specific combination of oil price and stock, the project value if currently in the red zone is slightly less than that in the yellow zone, which is slightly less than that in the green zone. The current river zone is not a large determinant of project value since the applied water constraint is not frequently binding, as is discussed further below.

\subsubsection{Project Value Comparison for the Four Scenarios}

To compare the project values across the four scenarios, we adopt one particular value for the resource stock dimension and examine how the project present value varies with the current oil price. We select 720 million barrels, where the resource stock is at its highest level, but the comparison is similar for other levels of reserves. Since for D_L and D_S, the river flow is always in the red zone, our comparison is done for the current river flow in the red zone. As seen in Figure 6, the stricter the water withdrawal limits or the drier the river flow condition, the lower the project's value, however in general the differences are small. In the scenarios with dry river conditions, a significant difference is now observed between the scenarios. At an oil price of $\$ 100 /$ barrel, the project's value is lower by $11.1 \%$ in the D_S scenario compared to D_L.

\subsubsection{Critical Prices To Abandon the Project}

Project abandonment will occur when reserves run out, when the lease ends, or when the oil price is so low that the firm is better off abandoning rather than maintaining an active project. Abandonment requires the firm to pay rehabilitation costs, but the firm thereby avoids the fixed costs of the oil sands operation. Fixed costs at $\$ 470$ million per year exceed rehabilitation costs of $\$ 278$ million. Rather than abandoning the firm also has the option to suspend production but still incurs fixed costs of $\$ 468$ million per year.

We might expect that stricter water withdrawal restrictions will affect a firm's decision about when to permanently abandon a project. Intuitively, stricter limitations on water withdrawals will require reduced production in dry periods which the firm will try to make it up in wetter periods. As a result the expected abandonment time would be delayed if restrictions become tighter. We investigate this effect for our hypothetical project by 


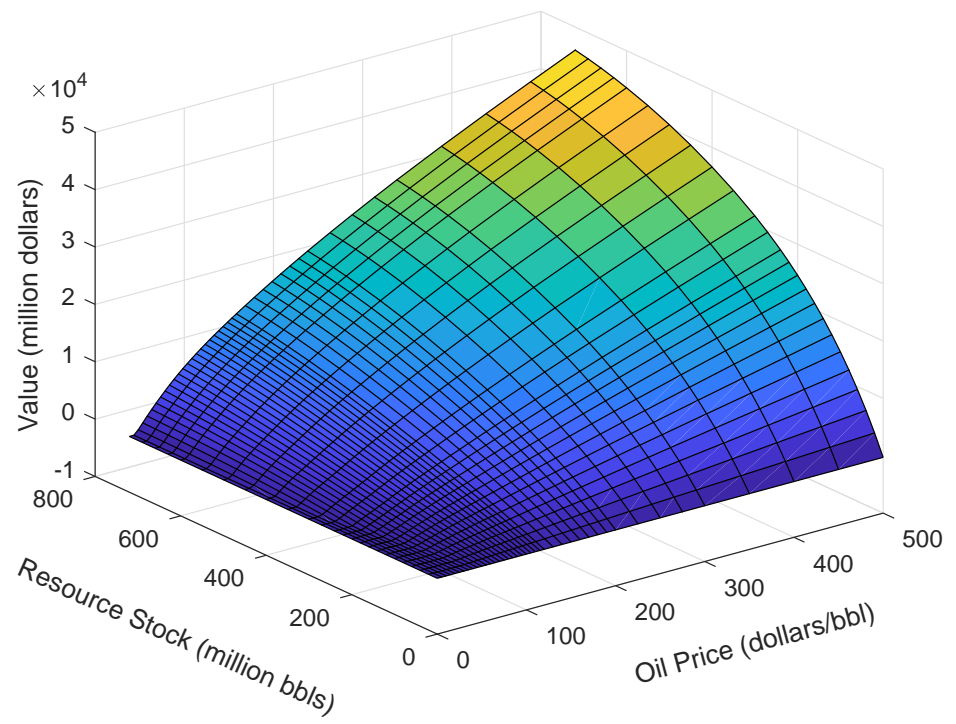

Figure 5: W_L: Project present value versus present price and resource stock if the current river flow condition is in the green zone and there is no option to install a water storage facility

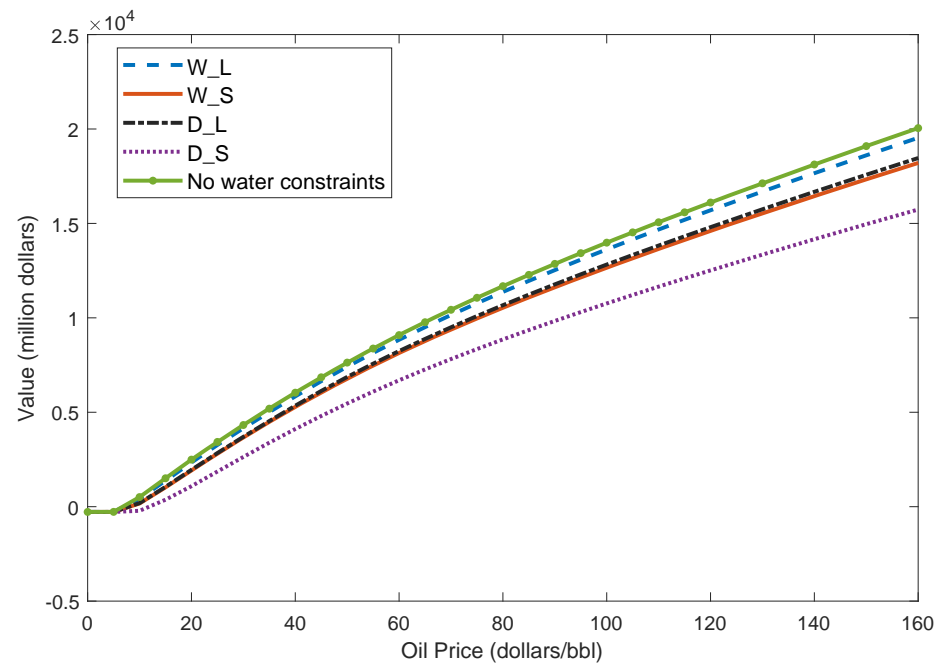

Figure 6: Comparison between scenarios: Project present value versus present price if the present resource stock level is 720 million barrels, the current river flow condition is in the red zone, and there is no option to install a water storage facility 
examining critical prices to abandon the project. If the oil price is greater than the critical price, the firm's optimal choice is to continue the project. Otherwise, it should shut down the project permanently. Table 6 lists the critical prices to abandon the project from the suspended state for the four scenarios for different levels of oil reserves. ${ }^{26}$ It shows that the crude oil prices for abandonment are fairly low ( $\$ 45$ per barrel and less) and are lower for higher reserve levels. Across scenarios, the change in critical prices is quite slight implying that stricter regulations and drier river conditions are having an insignificant impact on the decision to abandon the hypothetical project examined here. In our example, the river flow is quite abundant even in the red zone. The water withdrawal limit is high enough for the oil sands project to produce at close to its full capacity. To be specific, without using a water storage facility to shift available water between weeks, in scenario W_L, there are 51 out 52 weeks that the project can produce at its full capacity, in D_L, 33 out of 52, in W_S, 47 out of 52, and in D_S, 31 out of 52 weeks. When the resource stock is higher than 500 million barrels, it is not optimal to abandon the project except for at oil prices less than $\$ 5 /$ barrel.

\subsubsection{Main Findings}

The results in this section show that the Phase 1 Water Restrictions would not have a significant detrimental effect on our hypothetical oil sands operation. This is reinforced by comparing the project values when no water constraints at all are imposed to those for scenario W_L shown in Figure 6. It will be observed that the two curves are very close together. The impact of the regulations only becomes significant under drier river conditions or stricter regulations.

\subsection{Option To Install a Water Storage Facility}

When confronted with restrictions on water usage, firms may seek some technological option to reduce the impact of the restrictions. Among the possible options, the installation of a water storage facility is currently feasible and has been recommended by Alberta regulatory

\footnotetext{
${ }^{26}$ Except for low reserve levels (below 140 million barrels), critical prices to suspend the project (not shown) are always higher than those to abandon the project, implying the project will normally be in the suspended state before abandonment.
} 
Table 6: Critical Prices To Abandon the Project While There Is No Option To Install Water Storage To Mitigate

\begin{tabular}{|c|c|c|c|c|c|c|c|c|}
\hline \multicolumn{9}{|c|}{ From suspending stages to abandonment } \\
\hline \multirow{4}{*}{$\begin{array}{l}\text { Resource stock } \\
\text { (million barrels) }\end{array}$} & \multicolumn{3}{|c|}{ W_L } & \multicolumn{3}{|c|}{$\mathrm{W}_{-} \mathrm{S}$} & \multirow{2}{*}{$\frac{\mathrm{D}_{-} \mathrm{L}}{\text { red }}$} & \multirow{2}{*}{$\frac{\mathrm{D} \_S_{\mathrm{S}}}{\text { red }}$} \\
\hline & green & yellow & red & green & yellow & red & & \\
\hline & $\overline{\text { stage }}$ & $\overline{\text { stage }}$ & $\overline{\text { stage }}$ & $\overline{\text { stage }}$ & $\overline{\text { stage }}$ & $\overline{\text { stage }}$ & $\overline{\text { stage }}$ & $\overline{\text { stage }}$ \\
\hline & $2 \rightarrow 5$ & $2 \rightarrow 5$ & $2 \rightarrow 5$ & $2 \rightarrow 5$ & $2 \rightarrow 5$ & $2 \rightarrow 5$ & $2 \rightarrow 5$ & $2 \rightarrow 5$ \\
\hline 0 & $\mathrm{H}$ & $\mathrm{H}$ & $\mathrm{H}$ & $\mathrm{H}$ & $\mathrm{H}$ & $\mathrm{H}$ & $\mathrm{H}$ & $\mathrm{H}$ \\
\hline 20 & 35 & 35 & 35 & 35 & 40 & 40 & 40 & 45 \\
\hline 40 & 35 & 35 & 35 & 35 & 35 & 35 & 35 & 40 \\
\hline 60 & 30 & 30 & 30 & 30 & 35 & 35 & 35 & 35 \\
\hline 80 & 30 & 30 & 30 & 30 & 30 & 30 & 30 & 35 \\
\hline 120 & 30 & 30 & 30 & 30 & 30 & 30 & 30 & 30 \\
\hline 140 & 25 & 25 & 25 & 25 & 25 & 25 & 25 & 30 \\
\hline 180 & 25 & 25 & 25 & 25 & 25 & 25 & 25 & 25 \\
\hline 200 & 20 & 20 & 20 & 20 & 20 & 20 & 20 & 25 \\
\hline 240 & 15 & 15 & 15 & 15 & 15 & 15 & 15 & 20 \\
\hline 300 & 10 & 10 & 10 & 10 & 10 & 10 & 10 & 15 \\
\hline 350 & 5 & 5 & 5 & 10 & 10 & 10 & 10 & 10 \\
\hline 450 & 5 & 5 & 5 & 5 & 5 & 5 & 5 & 10 \\
\hline 500 & 5 & 5 & 5 & 5 & 5 & 5 & 5 & 5 \\
\hline 600 & 5 & 5 & 5 & 5 & 5 & 5 & 5 & 5 \\
\hline 660 & 5 & 5 & 5 & 5 & 5 & 5 & 5 & 5 \\
\hline 720 & 5 & 5 & 5 & 5 & 5 & 5 & 5 & 5 \\
\hline
\end{tabular}

"H" means that the critical prices is higher than $\$ 500 /$ barrel. Since in the history the oil price never exceeded $\$ 500$ /barrel, it implies that it is never optimal to abandon the project. 
authorities. This section introduces the option to install a water storage facility to the model and we examine its effects on the behaviour of the firm and project value.

\subsubsection{Project Values With and Without the Storage Option}

Figure 7 shows the project's values for the four scenarios with and without the option to install a water storage facility. As expected when the option to install storage is present, the project becomes more valuable. However we see that the difference in values with and without the storage option becomes significant only for the D_S case where values differ by $15.1 \%$ at an oil price of $\$ 90 /$ barrel. (The differences are $2.1 \%, 7.5 \%, 8.2 \%$ respectively for W_L, W_S, and D_L.) Appendix C provides a "ground truth" check on the order of magnitude of our value estimates.

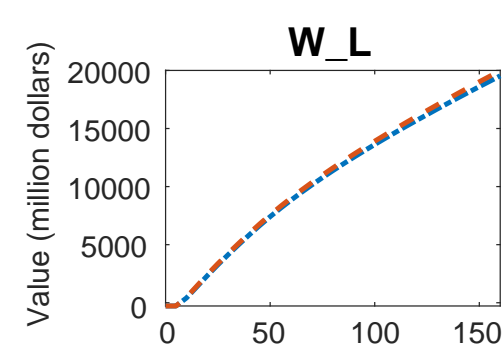

Oil Price (dollars/bbl)

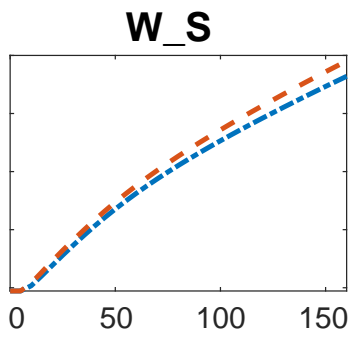

Oil Price (dollars/bbl)

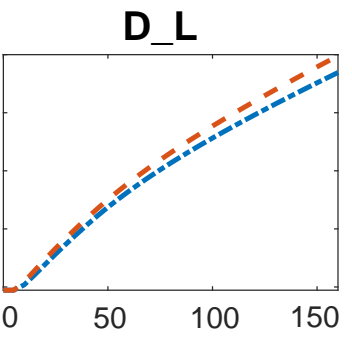

Oil Price (dollars/bbl)

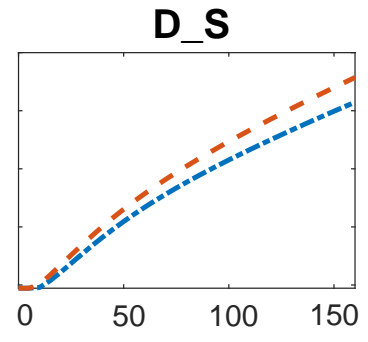

Oil Price (dollars/bbl)

\section{-----Without the storage option - - - With the storage option}

Figure 7: Comparing the project values in different scenarios between two cases: there is an option to install a water storage facility \& there is no such an option (the present resource stock level is 720 million barrels, the current river flow condition is in the red zone)

\subsubsection{Critical Prices To Install Water Storage}

Considering the stochastic features of the market and the river flow conditions, the firm chooses the timing of installing the water storage facility to optimize the present value of the project. The critical prices to switch from operating stage 1 to stage 3 indicate the optimal strategy for the decision to invest in water storage. If the crude oil price on the decision 
day is greater than the critical price, it is optimal to invest, otherwise the investment should be delayed. The critical prices depend on the state variables including present river flow condition as well as the resource stock level. Assuming that the resource stock is at its full level (i.e. 720 million barrels), Figure 8 shows for the four scenarios, the value of switching from operating stage 1 to stage 3 (i.e. stage 3 value less stage 1 value, hereinafter referred to as "switching values") for different oil prices at time zero. When the switching values are positive, it is optimal to switch to stage 3 by installing storage. The oil price at which the switching value changes from negative to positive is the critical price. For instance, in the first panel of Figure 8, when the current river flow condition is in the green zone, as long as the oil price is higher than $\$ 50 /$ barrel, it is optimal to begin the construction of the water storage facility. So $\$ 50 /$ barrel is the critical price. Similarly, in this scenario, when the present river flow condition is in the yellow or the red zone, the critical prices are $\$ 40 /$ barrel and $\$ 35 /$ barrel respectively.

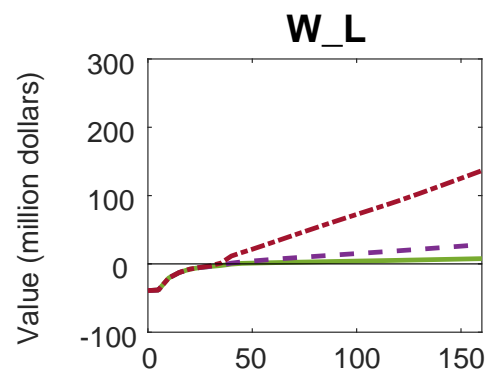

Oil Price (dollars/bbl)

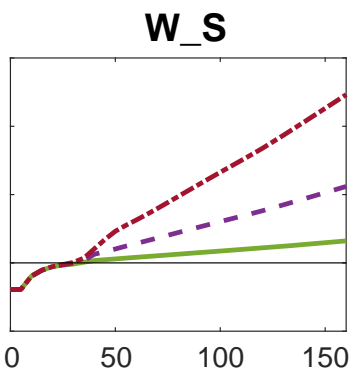

Oil Price (dollars/bbl)

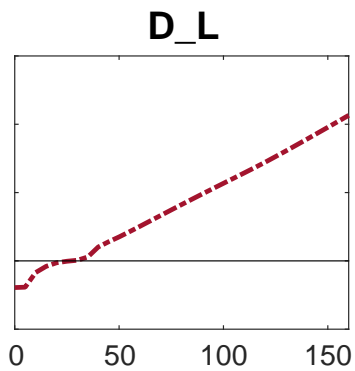

Oil Price (dollars/bbl)

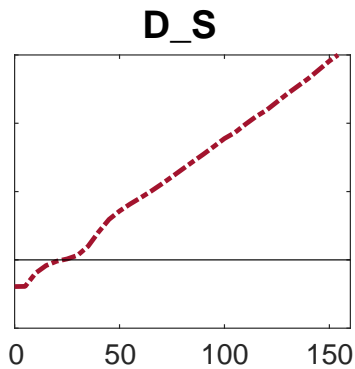

Oil Price (dollars/bbl)

\section{Green zone - - - Yellow zone ----- Red zone}

Figure 8: Values of switching from stage 1 to stage 3 by installing storage when the resource stock is at the full level (i.e. 720 million barrels)

Figure 9 depicts critical prices to proceed to operating stage 3 at different resource stock levels for the four scenarios. It is notable that the critical prices rise quite quickly as the resource stock is depleted, increasing from around $\$ 40$ per barrel at full reserves in the W_L case in the green zone to $\$ 140$ per barrel when reserves are at 350 million barrels. We also observe critical prices falling significantly when river conditions are drier and water restrictions are more severe. 

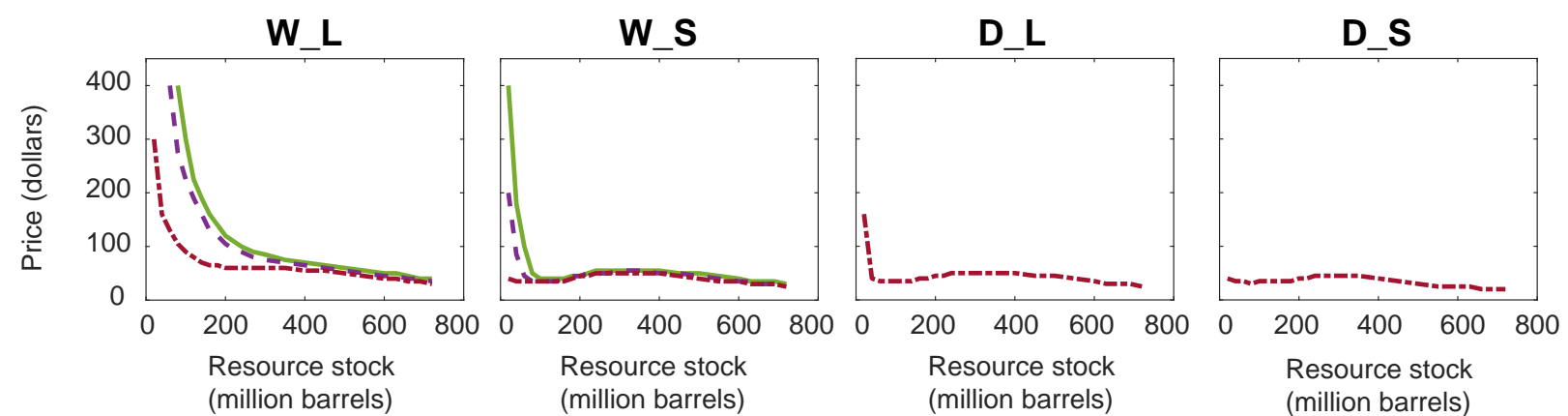

$$
\text { the green zone - - - the yellow zone ----- the red zone }
$$

Figure 9: Critical prices to proceed from operating stage 1 to stage 3 for different present resource stock levels in the four scenarios

\subsubsection{Critical Prices To Abandon the Project}

In Section 6.1.3 we claim that even without the option to install storage, the critical prices for abandoning the project are fairly low and are not very sensitive to different scenarios. When the option to install storage is available it will be even less likely that the project will be abandoned before the end of the lease at time $T$. Our results confirm this showing critical prices for abandonment that are the same as or lower than when there is no storage option. (Critical price tables are not shown for this case.) Given the assumed oil price process, the project is generally profitable when producing oil. Stricter water restrictions imply the project may need to stay in operation longer in order to extract the resource. Hence even when the oil price drops to very low levels, the project will be temporarily suspended but not abandoned.

\subsubsection{Main Findings}

The above results indicate that the application of a water storage facility can generally increase the project's value. The drier the river flow condition or the tighter the water restriction, the more valuable the investment in a water storage facility. However, in the four scenarios, the abandonment decision is not affected much by the installation of a water storage facility. 


\subsection{The Marginal Effect of the Phase 1 Water Management Frame- work and Efficiency of Water Withdrawal Constraints}

In this section we calculate the marginal costs of water withdrawal restrictions in order to consider the efficiency of the regulation. We define marginal cost to be the change in the expected value of the project to the firm, at time zero, caused by a marginal reduction in allowed water withdrawals in all future time periods (i.e. a marginal increase in water restrictions). This is a dynamic definition of marginal cost, in that it is assumed the firm will respond optimally to the change in water restrictions, and may adopt new technology through the installation of storage.

In theory, the goal of government policy is to set an efficient level of water restrictions that maximizes the total benefits of the regulation, which will be at a point that equates marginal costs and marginal benefits. The marginal benefits reflect the value to society of increased water flows in the Athabasca River. Although we have no monetary estimate of the benefit of increase river flows, the marginal cost estimate provides a lower limit for the marginal benefits in order for the regulation to be welfare enhancing. The marginal cost also indicates a firm's willingness to pay for water, and hence would be the price expected if water trading were permitted.

\subsubsection{The Marginal Costs Under the Phase 1 Water Management Framework}

The water withdrawal limits are defined over 52 weeks of the year and in three different water zones. For the purposes of this paper, we define an increase in water withdrawal restrictions to be a reduction of permitted water withdrawal rates of 70 million barrels per year in all weeks of the year when the river is in the yellow and red water zones over the lifetime of the project. We denote the reduction of withdrawal rates as $\Delta \bar{w}$.

The marginal cost of increased restrictions depends on the current value of the state variables. We estimate the marginal cost of the Phase 1 Water Management Framework to the hypothetical firm, $M C$, by taking the present value of the hypothetical firm $V(p, s, \bar{w}, \iota, \bar{\delta}, t)$, in a given river zone where $\bar{W}=\bar{w}$, at a specific oil price level, $P=p$, at a certain oil stock level, $S=s$, and finding the change in $V(p, s, \bar{w}, \iota, \bar{\delta}, t)$, when the annual constraints 
on water withdrawal rates in the yellow and red zones are further restricted by $\Delta \bar{w}^{27}$ over the lifespan of the project, i.e. $T-t_{0}$. That is to say, $M C=\frac{\Delta V(p, s, \bar{w}, l, \bar{\delta}, t)}{\Delta \bar{w} \cdot\left(T-t_{0}\right)}$.

The marginal costs corresponding to different current oil prices in the four scenarios, when there is an option to build a water storage facility, are depicted in the upper panels of Figure 10. The marginal costs for the cases where there is no storage option to mitigate the impact of the water constraints are depicted in the lower panels of Figure 10. We observe that the marginal cost of increasing the water restrictions is very low in the W_L scenario when there is an option to install storage - no more than 21 cents for oil prices lower than $\$ 150$ per barrel. Without a storage option the marginal cost in this case is higher, ranging from 27 cents for the lowest oil prices to $\$ 1.35$ in the red zone at $\$ 150$ per barrel for the price of oil. The marginal costs of the regulation are substantially higher when the river is assumed to be in drier conditions and when the base case regulations are stricter - that is in W_S, D_L and D_S.
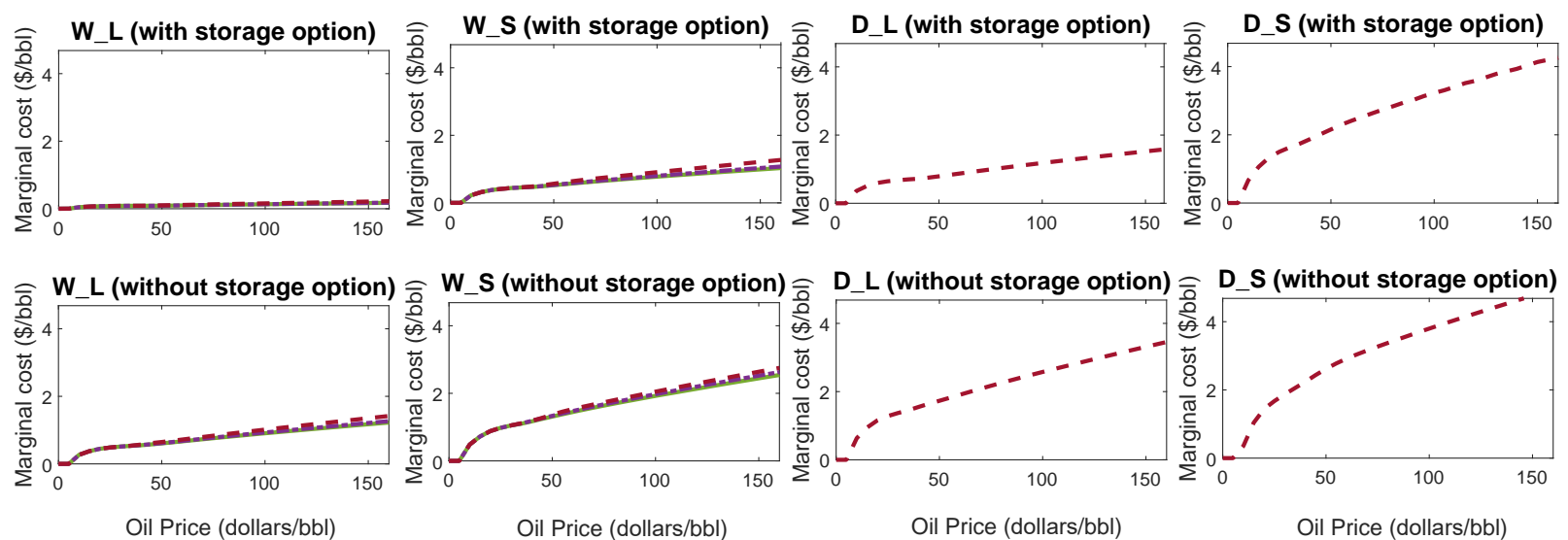

(dollars/bbl)

Oil Price (dollars/bbl)

Oil Price (dollars/bbl)

Green zone ----- Yellow zone - - - Red zone

Figure 10: Comparison of marginal cost between the cases of being with and without a storage option

\footnotetext{
${ }^{27}$ Due to the accuracy of the numerical method the smallest marginal change that can be examined is 1 million barrels of water per week over the lifespan of the project. The change in the firm's present value is in millions of dollars.
} 


\subsubsection{The Marginal Costs Under the Different Water Withdrawal Constraints and the Efficient Level of Constraints}

In this section we map out the marginal cost of increased restrictions for a range of initial water restrictions. If all firms in the industry were like this typical firm depicted in our example, we could map out the marginal cost of water restrictions for the oil sands industry as a whole. In reality oil sands firms have different efficiencies and cost curves so this calculation of an aggregate marginal cost curve must be viewed as illustrative.

Figure 11 below shows the marginal cost curve for the industry composed of 12 same scale projects (as is the number of operating projects in 2015). The figure is shown for an initial oil price of $\$ 50$ per barrel and assuming the oil stock is at its maximum level for each firm. The horizontal axis shows the adjustment of the level of year-round water withdrawal restrictions (i.e. the annually available water for oil industry), with water constraint regulations becoming less strict moving from left to right, in all future time periods. For example, -168 means that the water withdrawal limits in the red and yellow zones have been reduced by 168 million. We note that this depiction of marginal cost does not follow the traditional approach of depicting marginal cost versus the quantity on the horizontal axis, because the available water varies across weeks depending on the river flow zones. For each point on the horizontal axis, there is not a single number that can represent the available water quantity. Instead, there is a specific combination of available water quantities for different weeks and different river flow zones that map each point on the horizontal axis. One of those points represents the combination set by the Phase 1 Framework. We specify this point as a reference, labeled as 0 . The labels of other points reflect the changes of available water quantity of the corresponding regulated combination compared to that of the Phase 1 Framework, which are aforementioned $\Delta \bar{w}$.

For a given stage of operation we would expect the marginal cost of water restrictions to decline as restrictions become less onerous, moving from left to right on the graph. However this marginal cost curve depicts the situation of a firm currently in stage 1 and assuming optimal decisions are made in the future regarding the installation of storage technology. We see that starting from a point of lenient restrictions $($ at +1344$)$ on the right the marginal cost curve initially rises, then between +672 and +168 the cost curve falls. For restrictions of +672 and more lenient (going right) it is not optimal to install storage at any critical 
price. For restrictions of +672 and more stringent (going to the left), it is optimal to install storage in the future for some critical prices. Storage installation reduces the marginal cost of restrictions, hence we see a portion of the marginal cost curve which falls and then starts rising again to the left of +168 . This curve traces out a long run dynamic marginal cost curve which captures a change in the optimal technology happening between +168 and +672 . For further intuition we plot on the same graph the marginal cost curves for when there is no storage available (blue dashed curve) and when storage is freely available (red dashed curve) (and hence is a free option which will always be exercised.) It can be seen that the marginal cost curve for the firm in stage 1 with the storage option falls between these two other cases.

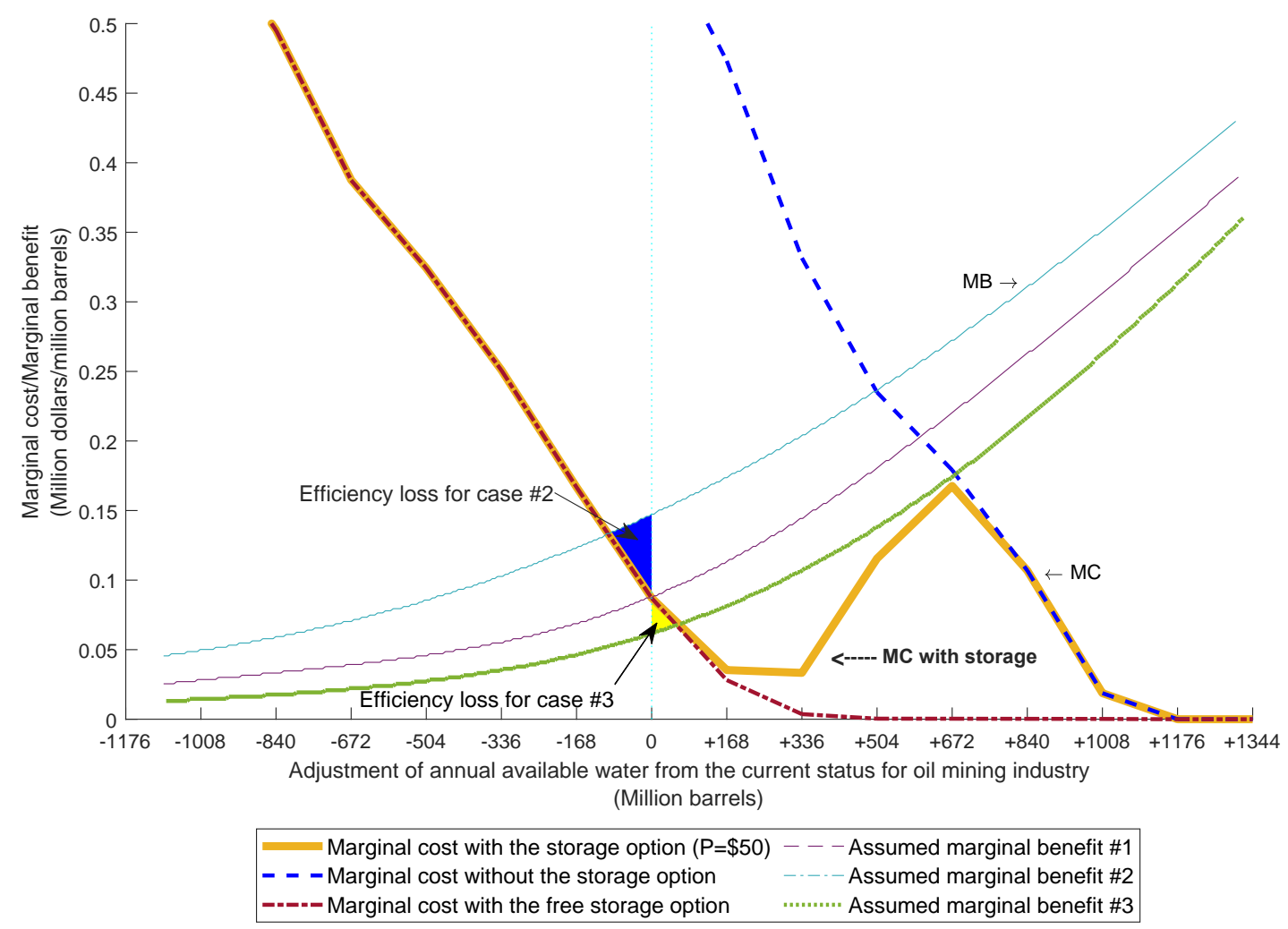

Figure 11: Marginal cost for firm in stage 1 vs. water constraint levels when the present oil price is $\$ 50 /$ barrel, the resource stock is at the full level, and the present river flow condition is in the green zone

We are unable to determine the efficient level of water restrictions as we do not have an 
estimate of the benefits to the ecosystem of an additional unit of water flowing in the river. Three hypothetical marginal benefit curves are shown in Figure 11 - one (\# 1) in which $\bar{w}$ (reflecting the Framework's restrictions) is the efficient level where marginal benefit equals marginal cost and the other two where $\bar{w}$ is above or below the socially optimal point (\# 2 and \# 3 respectively). The efficiency loss when the restrictions are not at the optimal levels depends on the slopes and locations of the marginal benefit curve and the marginal cost curve. Note that if the marginal benefit curve crossed the rising portion of the marginal cost curve, then there would be no unique point where $\mathrm{MB}=\mathrm{MC}$. In this case, the total benefits and total costs would need to be examined for a range of restrictions to find the optimum.

The marginal benefit curve will not change with the variation of oil price or resource stock. However the marginal cost of restrictions will depend on the state variables, i.e. the oil price $P$ and the oil reserve $S$, in particular. In Figure 12, we assume that the current constraint level is efficient, that is to say, when the oil price is $\$ 50 /$ barrel, the resource stock is at the full level, and the river condition is in the green zone, the marginal benefit equals the marginal cost. From this figure, we can see that different levels of the current oil price imply a different efficient water constraint. It is clearly impractical to change the level of water restrictions based on changing economic conditions in the oil industry which shift the marginal cost curve. However this highlights the fact that quantitative restrictions such as these have a highly variable cost for firms, depending on the value of key state variables such as the price of oil.

\subsubsection{Comparison With Previous Estimates of the Cost of Restrictions}

The marginal costs due to the water withdrawal constraints imply the marginal values of water to the firm (i.e. the marginal willingness to pay for water, or the implied shadow price of water). Mannix et al. (2014) measured the willingness to pay for water by oil sands firms including both in-situ and surface mining projects. In addition to some specific assumptions for projects regarding productivity of individual firms, costs, and project life-cycle, their assumptions about the oil price and the river flow condition are somewhat different from

ours. Specifically, they assume that the oil price is at a constant level of $\$ 70 /$ barrel and river flow conditions that are $10 \%$ drier than the historic condition. They also assumed differing water productivities for the different oil sands firms. Under their assumptions, when water 


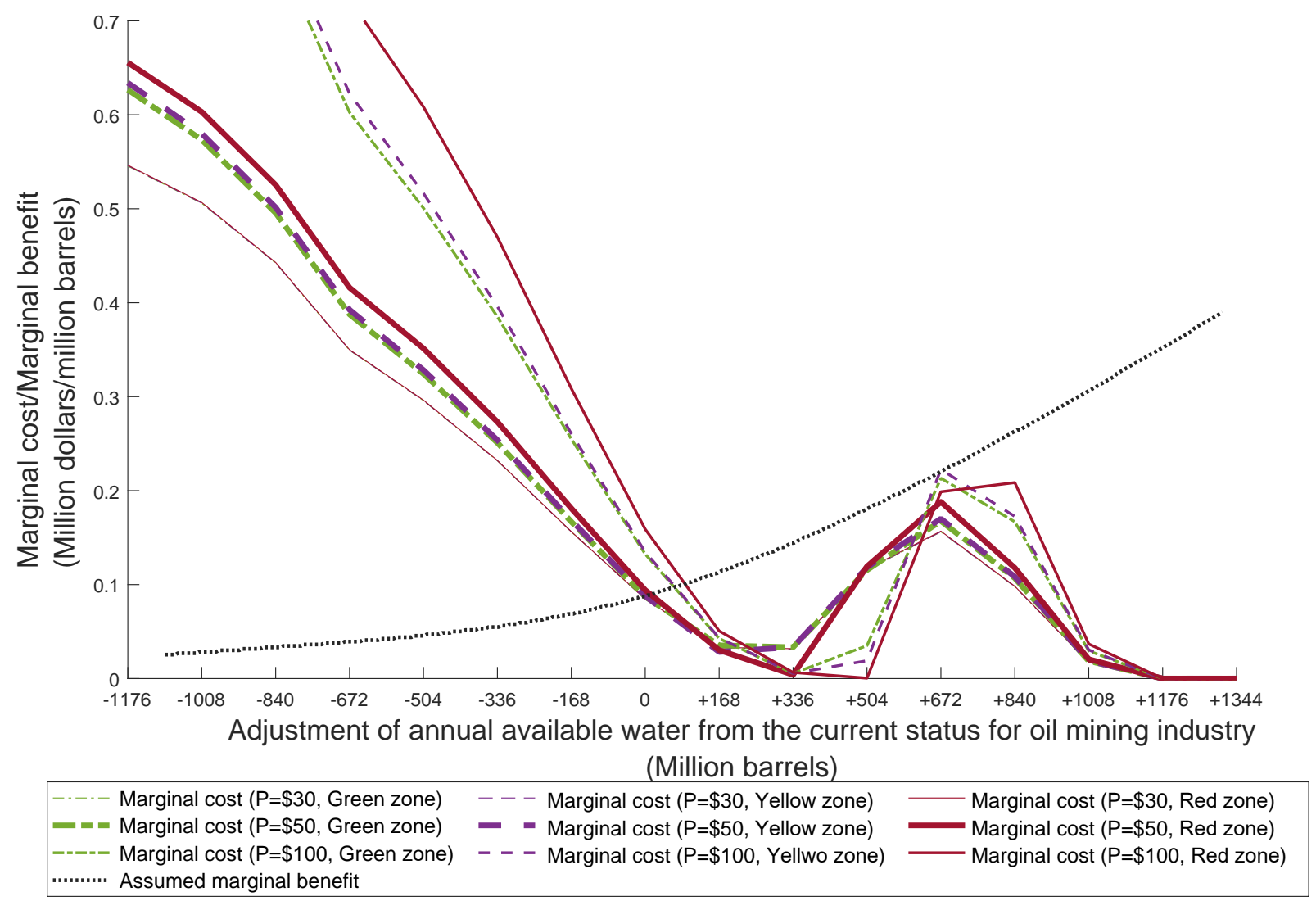

Figure 12: Marginal cost for the firm in stage 1 vs. water constraint levels for different current oil prices when the resource stock is at the full level and the present river flow condition is in the green zone 
is assigned according to license priorities, they found the highest marginal willingness to pay is $\$ 180 / \mathrm{m}^{3}$ ( $\$ 22.5 /$ barrel). Then they derive an efficient water distribution mechanism among oil sands firms by solving a linear programming problem and find in this case the highest marginal willingness to pay among firms with a shortfall of water decreases to a maximum of $\$ 78 / \mathrm{m}^{3}$ (\$9.75/barrel) and on average $\$ 6.7 / \mathrm{m}^{3}$ (\$0.84/barrel). Furthermore, when a consolidated tailings technology is in use together with the efficient allocation policy, the average willingness to pay decreases to $\$ 4.15 / \mathrm{m}^{3}$ ( $\$ 0.52 /$ barrel). Instead, if a storage technology is in use under an efficient allocation policy, the average willingness to pay will further decrease, although the paper does not provide an estimate. In contrast in our analysis we assume the water sharing agreement where all firms share water reductions equally, and we further assume all firms are equally productive. In our numerical example, with no storage option, and given the present oil price is $\$ 70 /$ barrel, the implied shadow price of water is from $\$ 0.73$ /barrel to $\$ 0.80 /$ barrel depending on the current specific river flow zone. To compare more closely to Mannix et al.'s result, we undertake a sensitivity analysis in which adopt their assumption regarding river flow condition. In this sensitivity, the marginal cost when the present oil price is $\$ 70 /$ barrel (which is the assumed constant oil price in Mannix et al. (2014)) is $\$ 0.28 /$ barrel to $\$ 0.29 /$ barrel, depending on which river flow zone it is in. The result is still lower than that of Mannix et al. (2014), which is $\$ 0.84$ /barrel, when they eliminate the impact of inefficient allocation due to the prior allocation (by applying an efficient allocation policy). Furthermore, in our study, when there is an option to build a water storage facility, the implied shadow price of water decreases to a very insignificant level that less than $\$ 0.12 /$ barrel. This is much lower than the results given by Mannix et al. (2014). Nevertheless the implied shadow prices are of the same order of magnitude despite the very different modelling approaches.

\section{Sensitivity Analyses}

We undertook various sensitivities for parameter assumptions. In this section we report on sensitivities for price volatility and water productivity. 


\subsection{The Effects of Price Volatility}

Figures 13 - 15 plot critical prices to install storage versus volatility for several cases. Looking first at the D_S scenario in the red zone (Figure 13), the critical prices are observed to fall as volatility increases. This is interesting as for simple investment options, an increase in volatility results in the delay of an investment (Majd and Pindyck (1987)). However in this case when water flows are reduced and water withdrawals are heavily constrained, an increase in price volatility makes storage more valuable to the firm. Without storage and under binding water constraints, the firm may not be able to take advantage of a sudden upswing in prices. Hence the more volatile prices increase the desirability of storage. We see a similar effect under base case water restrictions - W_L in the red zone (Figure 14). However for W_L in the green zone, shown in Figure 15, we observe an increase in critical prices as volatility reaches levels higher than 0.47 . In this case where water withdrawals are only mildly constrained, once volatility reaches a certain level, further increases tend to delay investment, as per the normal effect of uncertainty.

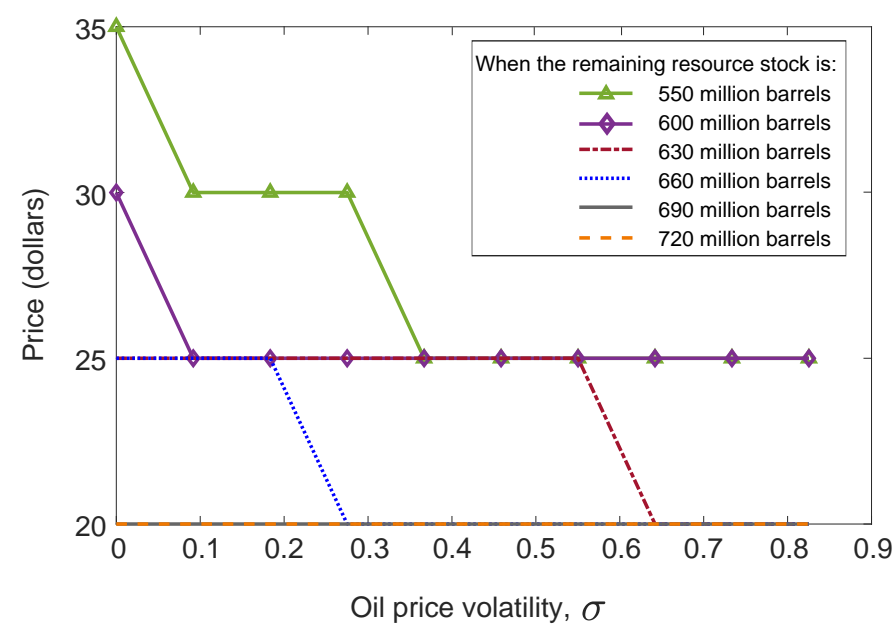

Figure 13: Critical prices to install storage versus volatility for scenario D_S in the red zone

We also considered the effect of increased volatility on marginal and total costs of the restrictions. In the wet scenarios, the marginal and total costs of the regulations do not change substantially under different volatility assumptions. However, for D_S, total costs and marginal costs do fall significantly when oil price volatility increases. For example, a doubling of volatility, $\sigma$, reduced the marginal cost from $\$ 3.23$ per barrel to $\$ 2.81$ per 




Figure 14: Critical prices to install storage versus volatility for scenario W_L in the red zone

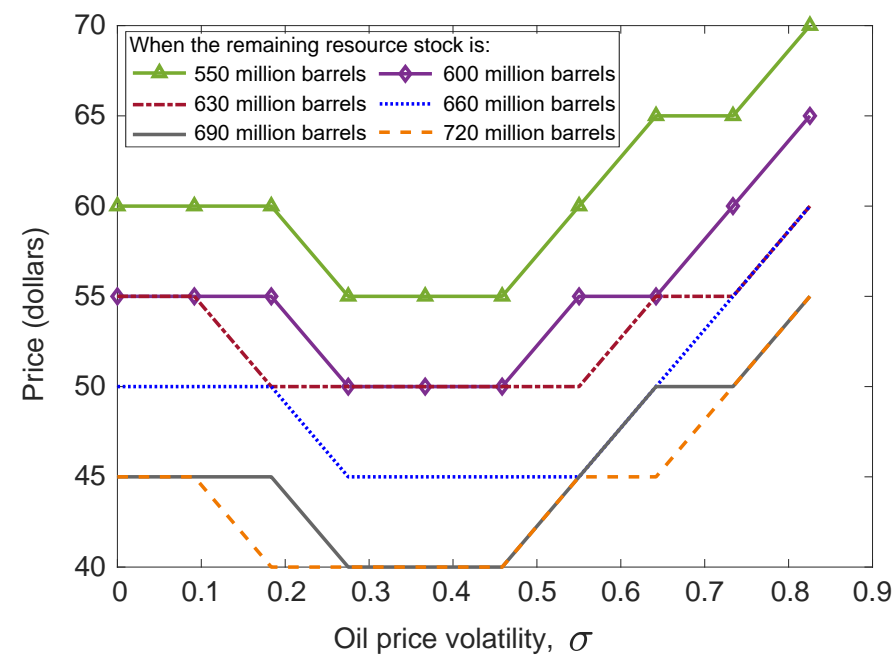

Figure 15: Critical prices to install storage versus volatility for scenario $\mathrm{W}_{-} \mathrm{L}$ in the green zone 
barrel. Increasing volatility has several effects, and whether the marginal cost will rise or fall depends on the case being examined. An increase in volatility can increase the value of the oil producing asset, as there will be more high price realizations which increases revenue, while the effect of low price realizations is muted by the option to shut in operations. On the other hand, more restrictive water limitations reduce the ability of the firm to take advantage of high prices. In the case examined in this paper the net effect, at time zero, of an increase in volatility is a reduction in the cost of restrictions.

\subsection{The Effects of Water Productivity}

As water productivity increases, the desirability of installing a water storage facility declines as does the cost of water restrictions. Recall our base case assumption is a productivity level of 0.3 barrels of bitumen/barrel of water, which reflects the average level for oil sands sector. For individual projects, there are a range of water productivity levels. When the water productivity is greater than 0.5 barrels of bitumen/barrel of water, for W_L scenario, there is no need to invest in a water storage facility no matter what the river flow zone and there is no cost to the firm of the water restrictions. Figures 16 displays the marginal costs of restrictions under different water productivity assumptions. We observe that the marginal cost is many times higher when water productivity is reduced to $1 / 3$ of its base case value.

\section{Conclusions}

This paper studies the efficiency of regulations designed to protect in-stream flows in the Athabasca River by modelling the costs imposed on oil sands firms and in particular the marginal cost of increasing or relaxing water withdrawal restrictions. While we have not attempted to estimate the benefits of in-stream water flows, the marginal cost estimates on their own will be informative in regulatory design. The estimated marginal costs can be also seen as implied shadow prices of water for the firm and may be considered a minimum values required for the environmental benefits to justify the regulation. The methodology and conclusions from this analysis can inform the assessment of regulations for other resource extraction projects. These estimates also provide a reference for further research on the 


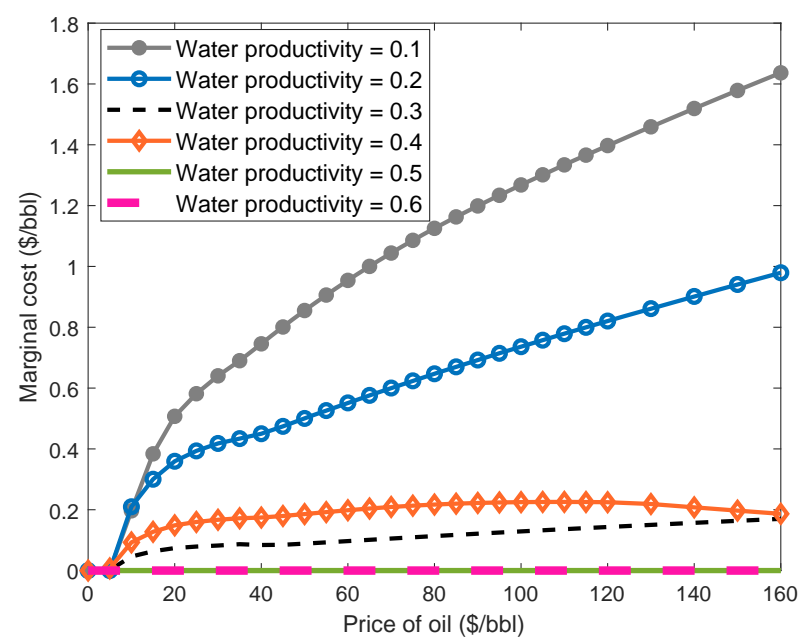

Figure 16: The marginal costs when the river flow is in the green zone under different water productivity levels for scenario W_L (Water productivity is in barrels of bitumen/barrel of water. The marginal cost refers to the loss in value to the project on a $\$ /$ barrel basis of an increase in water withdrawal restrictions as outlined in Section 5.2, page 24.)

benefits of switching to market based water conservation instruments, such as water pricing. A water pricing scheme would increase efficiency by ensuring efficient allocation of water across firms, unlike the current scheme which allocates water equally.

Some key findings of this paper are summarized below.

- Low cost of the regulations. The Phase 1 Water Management Framework did not impose a large cost on firms. But if changing climate resulted in drier conditions and/or if the Phase 1 regulations were made stricter, there would be a larger cost for firms. Nevertheless there appears to be scope for adopting stricter regulations if future research determines there is significant ecological benefit or benefit to other stakeholders in the area from doing so.

- Non-monotonic impact of increasing price volatility. It is well known in the literature that for a simple investment option, increased price volatility is likely to delay the optimal investment timing. However, we found that under very dry river conditions, increased volatility can reduce the critical price required to install storage, implying that the expected time for the investment is sooner. As price volatility is increased, 
high price realizations become more likely, which increases the value of the ability to ramp up production, making storage more valuable to the firm. In contrast, under more plentiful water conditions when water restrictions are less binding, an increase in oil price volatility can delay the optimal investment in water storage as per the normal effect.

- Delay in project abandonment. Stricter regulations on water withdrawals may cause a firm to delay the permanent abandonment of a project. This follows because tighter water restrictions means it may take longer to extract the resource. For the hypothetical project examined in this paper, there is not a strong effect on the abandonment decision.

- Long run dynamic marginal cost curve. A long run dynamic marginal cost curve shows the impact of making water restrictions more restrictive when the firm has the option to install technology that limits the impact of the restrictions. Marginal cost is generally increasing with tighter restrictions, but the marginal cost falls as restrictions are relaxed over a particular range. This indicates the importance of examining a range of restrictions to allow for changing technology.

- Marginal cost depends on state variables. The marginal cost of stricter regulations depends on the values of key state such as the price of oil and the resource stock. The higher is the price of oil the higher is the marginal cost of restrictions. The marginal cost is higher for larger resource levels. 


\section{References}

Adamowicz, W., Percy, D. and Marian, W. (2010), Alberta's water resource allocation and management system: A review of the current water resource allocation system in Alberta, Report, Alberta Water Research Institute, Alberta. retrieved from URL:http://www.seawa.ca/wp-content/uploads/2014/08/Albertas_ Water_Resource_Allocation_and_Management_System.pdf.

Alaouze, C. M. (1991), 'Intertemporal water transfers and drought', Australian Economic Papers 30(56), 114-127.

Alberta (2015), Lower Athabasca region: surface water quantity management framework for the Lower Athabasca River, Policy, Environmental and Sustainable Resource Development, Edmonton, Canada. ISBN: 9781460121733.

Alberta and Canada (2007), Water management framework: Instream flow needs and water management system for the Lower Athabasca River, Policy, Alberta Environment and Fisheries and Oceans Canada.

Alberta Energy Regulator (2015), ST98-2015, Alberta's energy reserves 2014 and supply/demand outlook 2015-2024, Technical report, Alberta Energy Regulator, Calgary, Canada.

Bawden, A. J., Linton, H. C., Burn, D. H. and Prowse, T. D. (2014), 'A spatiotemporal analysis of hydrological trends and variability in the Athabasca River region, Canada', Journal of Hydrology 509, 333-342.

Bennett, L., Howe, C. and Shope, J. (2000), 'The interstate river compact as a water allocation mechanism: Efficiency aspects', American Journal of Agricultural Economics 82(4), 1006-1015.

Björk, T. (2009), Arbitrage Theory in Continuous Time, Oxford University Press.

Brennan, D. (2010), 'Economic potential of market-oriented water storage decisions: Evidence from Australia', Water Resources Research 46.

Brennan, M. J. (1991), The price of convenience and the valuation of commodity contingent claims, in D. Lund and B. Øksendal, eds, 'Stochastic Models and Option Values - Application to Resources, Environment and Investment Problems', Elsevier Science Publishers B.V., Amsterdam, The Netherlands, pp. 33-71.

Brennan, M. J. and Schwartz, E. S. (1985), 'Evaluating natural resource investments', Journal of Business pp. 135-157. 
Bruce, J. P. (2006), Oil and water - Will they mix in a changing climate? The Athabasca River story, in 'Implications of a $2^{\circ} \mathrm{C}$ Global Temperature Rise on Canada's Water Resources, Athabasca River and Oil Sands Development, Great Lakes and Hydropower Production', pp. 12-34.

Chen, S. and Insley, M. (2012), 'Regime switching in stochastic models of commodity prices: An application to an optimal tree harvesting problem', Journal of Economic Dynamics and Control 36(2), 201-219.

Chen, Z. (2008), Numerical methods for optimal stochastic control in finance, PhD thesis, University of Waterloo, Waterloo, Ontario, Canada.

Chen, Z. and Forsyth, P. A. (2007), 'A semi-Lagrangian approach for natural gas storage valuation and optimal operation', SIAM Journal on Scientific Computing 30(1), 339-368.

Chen, Z. and Forsyth, P. A. (2010), 'Implications of a regime-switching model on natural gas storage valuation and optimal operation', Quantitative Finance 10(2), 159-176.

d'Halluin, Y. (2004), Numerical methods for real options in telecommunications, PhD thesis, University of Waterloo, Waterloo, Ontario, Canada.

d'Halluin, Y., Forsyth, P. A. and Labahn, G. (2005), 'A semi-Lagrangian approach for American Asian options under jump diffusion', SIAM Journal on Scientific Computing 27(1), 315-345.

Di Baldassarre, G., Wanders, N., AghaKouchak, A., Kuil, L., Rangecroft, S., Veldkamp, T. I. E., Garcia, M., van Oel, P. R., Breinl, K. and Van Loon, A. F. (2018), 'Water shortages worsened by reservoir effects', Nature Sustainability 1(11), 617-622.

Dixit, A. K. and Pindyck, R. S. (1994), Investment under Uncertainty, Princeton University Press.

Dudley, N. J. and Hearn, A. B. (1993), 'Systems modeling to integrate river valley water supply and irrigation decision making under uncertainty', Agricultural Systems 42(1), 323.

Economic Development and Trade (2015), Alberta oil sands industry quarterly update (spring 2015) - Reporting on the period: December 5, 2014 to March 20, 2015, Policy, Economic Development and Trade, Edmonton, Canada. retrieved from URL:https://open.alberta.ca/dataset/b70a79b3-387f-475a-be38-6fe4cd5bb007/ resource/5fd600ff-ce99-41e3-8235-8eb6bcbe414d/download/ 2614198-2015-sring-aosid-quarterlyupdate.pdf. 
Geman, H. (2005), Commodities and Commodity Derivatives: Modeling and Pricing for Agriculturals, Metals and Energy, Wiley Finance.

Gibson, R. and Schwartz, E. S. (1990), 'Stochastic convenience yield and the pricing of oil contingent claims', The Journal of Finance 45(3), 959-976.

Golder Associates Ltd. (2015), Engineering mitigation options for meeting the Athabasca River Water Management Framework, Private report for the benefit of the client 07-13450027.5000, Golder Associates Ltd.

Gosselin, P., Hrudey, S. E., Naeth, M., Plourde, A., Therrien, R., Van Der Kraak, G. and $\mathrm{Xu}$, Z. (2010), Environmental and health impacts of Canada's oil sands industry, Royal Society of Canada Ottawa, Ontario, Canada.

Griffiths, M., Taylor, A. and Woynillowicz, D. (2006), Troubled waters, troubling trends - Technology and policy options to reduce water use in oil and oil sands development in Alberta, Technical report, Pembina Institute, Drayton Valley, Alberta, Canada. ISBN 0-921719-91-4, retrieved from https://www.pembina.org/pub/ troubled-waters-troubling-trends.

Griffiths, M. and Woynillowicz, D. (2003), Oil and troubled waters - reducing the impact of the oil and gas industry on Alberta's water resources, Technical report, Pembina Institute, Drayton Valley, Alberta, Canada.

Holding, S., Allen, D. M., Notte, C. and Olewiler, N. (2017), 'Enhancing water security in a rapidly developing shale gas region', Journal of Hydrology: Regional Studies 11(SI), 266277.

Huang, Y. (2020), The Economics of Water Conservation Regulations in Mining: An Application to Alberta's Lower Athabasca River Region, PhD thesis, University of Waterloo, Waterloo, Ontario, Canada.

Insley, M. (2017), 'Resource extraction with a carbon tax and regime switching prices: Exercising your options', Energy Economics 67, 1-16.

Ivanhoe Energy Inc. (2012), 'Application for approval of the Tamarack integrated oil sands project (Volume 6: Supplemental information request \#3)'. retrieved from https : //open . alberta.ca/publications/4926022.

Jensen, K. (2010), 'Environmental impact of the oil and gas industry's consumption of water from the Athabasca River during the predicted water shortage for Canada's Western Prairie Provinces'. retrieved from https://www.queensu.ca/ensc/sites/webpublish. queensu.ca.enscwww/files/files/501/Jensen.pdf. 
Kuwayama, Y., Olmstead, S. M. and Krupnick, A. (2013), Water resources and unconventional fossil fuel development: Linking physical impacts to social costs. Discussion paper, Resources for the Future, retrieved from https://media.rff.org/archive/files/ sharepoint/WorkImages/Download/RFF-DP-13-34.pdf.

Libecap, G. D. (2011), 'Institutional path dependence in climate adaptation: Coman's "some unsettled problems of irrigation", American Economic Review 101(1), 64-80.

Libecap, G. D. and Barbara, S. (2012), Water rights and markets in the U.S. semiarid west - Efficiency and equity issues. ICER working paper, retrieved from http://ssrn.com/ abstract $=1738371$.

Lunn, S. et al. (2013), 'Water use in Canada's oil-sands industry: The facts', SPE Economics \& Management 5(01), 17-27.

Majd, S. and Pindyck, R. S. (1987), 'Time to build, option value, and investment decisions', Journal of Financial Economics 18(1), 7-27.

Mannix, A. E., Adamowicz, W. L. and Dridi, C. (2014), 'Solutions to the high costs of future water restrictions for new oil sands industry along the Athabasca River', Canadian Water Resources Journal 39(4), 395-408.

Mannix, A. E., Dridi, C. and Adamowicz, W. L. (2010), 'Water availability in the oil sands under projections of increasing demands and a changing climate: An assessment of the Lower Athabasca Water Management Framework (Phase 1)', Canadian Water Resources Journal 35(1), 29-52.

Mason, C. F. (2001), 'Nonrenewable resources with switching costs', Journal of Environmental Economics and Management 42(1), 65-81.

Millington, D. and Murillo, C. A. (2015), Canadian oil sands supply costs and development projects (2015-2035), Technical report, Canadian Energy Research Institute.

National Energy Board (2006), 'Canada's oil sands - opportunities and challenges to 2015: An update'.

Peters, D. L., Atkinson, D., Monk, W. A., Tenenbaum, D. E. and Baird, D. J. (2013), 'A multi-scale hydroclimatic analysis of runoff generation in the Athabasca River, western Canada', Hydrological Processes 27(13), 1915-1934.

Pindyck, R. S. (1980), 'Uncertainty and exhaustible resource markets', The Journal of Political Economy pp. 1203-1225. 
Rasouli, K., Hernández-Henriquez, M. and Déry, S. (2013), 'Streamflow input to Lake Athabasca, Canada', Hydrology and Earth System Sciences 17(5), 1681-1691.

Schindler, D. W. and Donahue, W. F. (2006), 'An impending water crisis in Canada's western prairie provinces', Proceedings of the National Academy of Sciences 103(19), 7210-7216.

Schwartz, E. S. (1997), 'The stochastic behavior of commodity prices: Implications for valuation and hedging', The Journal of Finance 52(3), 923-973.

Schwartz, E. and Smith, J. E. (2000), 'Short-term variations and long-term dynamics in commodity prices', Management Science 46(7), 893-911.

Slade, M. E. (2001), 'Valuing managerial flexibility: An application of real-option theory to mining investments', Journal of Environmental Economics and Management 41(2), 193233.

Squires, A. J., Westbrook, C. J. and Dubé, M. G. (2010), 'An approach for assessing cumulative effects in a model river, the Athabasca River basin', Integrated Environmental Assessment and Management 6(1), 119-134.

Strikwerda, J. C. (2004), Finite difference schemes and partial differential equations, Vol. 88, Siam.

Thomashausen, S., Maennling, N. and Mebratu-Tsegaye, T. (2018), 'A comparative overview of legal frameworks governing water use and waste water discharge in the mining sector', Resources Policy 55, 143-151.

Toledano, P. and Roorda, C. (2014), Leveraging mining investments in water infrastructure for broad economic development: Models, opportunities and challenges, Technical report, Columbia Center on Sustainable Investment, Columbia University. retrieved from http://ccsi.columbia.edu/work/projects/ leveraging-infrastructure-investments-for-development/.

Toman, M., Curtright, A. E., Ortiz, D. S., Darmstadter, J. and Shannon, B. (2008), Unconventional fossil-based fuels: Economic and environmental trade-offs, Rand Corporation.

Vengosh, A., Jackson, R. B., Warner, N., Darrah, T. H. and Kondash, A. (2014), 'A critical review of the risks to water resources from unconventional shale gas development and hydraulic fracturing in the United States', Environmental Science \& Technology 48(15, SI), 8334-8348.

Weber, M. and Cutlac, M. (2014), 'Economic and environmental tradeoffs from alternative water allocation policies in the South Saskatchewan River Basin', Canadian Water Resources Journal / Revue canadienne des ressources hydriques 39(4), 409-420. 
Wilmott, P. (1998), Derivatives - The theory and practice of financial engineering, Wiley Chichester.

Wolfe, B. B., Hall, R. I., Edwards, T. W. and Johnston, J. W. (2012), 'Developing temporal hydroecological perspectives to inform stewardship of a northern floodplain landscape subject to multiple stressors: paleolimnological investigations of the Peace-Athabasca Delta', Environmental Reviews 20(3), 191-210.

Wolfe, B. B., Hall, R. I., Edwards, T. W., Vardy, S. R., Falcone, M. D., Sjunneskog, C., Sylvestre, F., McGowan, S., Leavitt, P. R. and van Driel, P. (2008), 'Hydroecological responses of the Athabasca Delta, Canada, to changes in river flow and climate during the 20th century', Ecohydrology 1(2), 131-148.

Woynillowicz, D., Severson-Baker, C. and Raynolds, M. (2005), Oil sands fever: The environmental implications of Canada's oil sands rush, Pembina Institute Edmonton.

\section{A Boundary Conditions}

Boundary conditions must be established for the state variables $t, P, S$, and $I$.

- At $t=T$ if the project has not previously been abandoned, reclamation costs will be paid of amount $-C_{r}$. Therefore $V=-C_{r}$ for $\delta \in\left[\delta_{1}, \delta_{2}, \delta_{3}, \delta_{4}\right]$. For $\delta=\delta_{5}, V=0$ at $t=T$ as reclamation will already have been carried out so that the value will not change.

- As $P \rightarrow 0$, the volatility term of the stochastic differential equation describing $P$ (Equation (8)), goes to zero. Hence we can just solve the HJB equation along the boundary at $P=0$. The differential operator becomes:

$$
\mathcal{L} V=-Q \frac{\partial V}{\partial S}+\left(W_{w}-W_{p}\right) \frac{\partial V}{\partial I}+\sum_{u=1, u \neq k}^{3} \lambda^{k \rightarrow u}\left(V\left(\bar{w}=\bar{W}_{u}\right)-V\left(\bar{w}=\bar{W}_{k}\right)\right)-r V
$$

- At $P=p_{\max }$ it is assumed that the value of the project will be linear in the oil price, implying $\frac{\partial^{2} V}{\partial p^{2}}=0$. The implicit assumption is that volatility is unimportant at very 
high prices and is commonly assumed in the finance literature (Wilmott, 1998). In this case the differential operator becomes:

$\mathcal{L} V=a \frac{\partial V}{\partial P}-Q \frac{\partial V}{\partial S}+\left(W_{w}-W_{p}\right) \frac{\partial V}{\partial I}+\sum_{u=1, u \neq k}^{3} \lambda^{k \rightarrow u}\left(V\left(\bar{w}=\bar{W}_{u}\right)-V\left(\bar{w}=\bar{W}_{k}\right)\right)-r V$

where $a \equiv \epsilon(\mu-\ln P) P ; \quad$ and $b \equiv \sigma P$.

Since $a=\epsilon(\mu-\ln P) P \leq 0$, according to the discussion of boundary conditions by Chen and Forsyth (2007), we know that characteristics are outgoing in the $P$ direction at $P \rightarrow p_{\max }$. Hence no additional information is needed from outside of the domain of $P$ and we can solve the PDE at the boundary. ${ }^{28}$

- As $S \rightarrow 0$, the oil production converges to zero: $Q \rightarrow 0$. At this point, the project ends, and the land must be reclaimed according to regulations.

- At $S=S_{0}$, we solve the HJB equation at this boundary, and no special boundary condition is needed.

- As $I=0$, we can not withdraw water from the storage facility, but can only add water into the facility through water withdrawals from the river. Hence $\left(W_{w}-W_{p}\right) \geqslant 0$. Accordingly there are outgoing characteristics in the $I$ direction. We do not need additional information from outside of the domain of $I$ and can just solve the HJB equation along the boundary.

- When $I=I_{\max }$, we cannot add any additional water to storage which means ( $W_{w}-$ $\left.W_{p}\right) \leq 0$. Hence there are outgoing characteristics in the $I$ direction. No additional information is needed from outside of the domain of $I$.

\footnotetext{
${ }^{28} \mathrm{~A}$ detailed discussion about the information propagation direction along characteristics can be found in Strikwerda (2004).
} 


\section{B Numerical Solution Details}

A number of papers (d'Halluin et al., 2005; Chen and Forsyth, 2007, 2010) introduce the method for solving stochastic optimal control problems. More details can be found in theses d'Halluin (2004) and Chen (2008). We tailor the method to accommodate our particular problem in MATLAB. The detailed semi-Lagrangian time stepping, the fully implicit discretization scheme the tests for the accuracy of the numerical solution are provided in the Appendices of Huang (2020).

\section{Ground-truthing project value}

To ground-truth our result about the project value, we compare the sector's total value hereby derived to that derived from $2014 \sim 2016$ financial statements of the five existing oil sands mining operators. ${ }^{29}$ This will provide a rough comparison of the orders of magnitude. The annual total profit from the oil sands mining business reflected by the financial statements is about 7.4 billion dollars. Treating it as an annuity lasting for 10 years, the present value is about 66 billion dollars. The total value derived from our model for our hypothetical project is 12.239 billion dollars. This hypothetical project is larger than the average reported by the AOSIQU (1.38 million barrels per week versus 0.83 million barrels per week). Scaling the hypothetical project value by $0.83 / 1.38$ and multiplying by 12 projects gives 88 billion dollars. We conclude our estimated project value is the right order of magnitude. We do not

\footnotetext{
${ }^{29}$ Because for each operator, the ownership of mining blocks can vary over time, we choose 2014 to 2016 to calculate the average annual total profit in order to keep a relative stable profile of blocks, which could be comparable to the hypothetical case that we examine. The five companies are: Canadian Natural Resources Limited, Imperial Oil Limited, Shell Albian Sands, Suncor Energy Inc., and Syncrude Canada Ltd.. Their financial statements can be found in the following websites (accessed on January 11, 2020).

https://www.cnrl.com/investor-information/annual-documents

https://www.imperialoil.ca/en-CA/Investors/Investor-relations/

Annual-and-quarterly-reports-and-filings

https://www.shell.com/investors/financial-reporting/annual-publications/

annual-reports-download-centre.html

https://www.suncor.com/en-ca/investor-centre/financial-reports/

archived-annual-reports

https://www.syncrude.ca/our-news/sustainability-report/
}

Page 56 
expect a close match since the project value calculated in this paper is an expected value based on an assumption about the future price path of oil, which we are comparing to an annuity base on historical profit levels. 